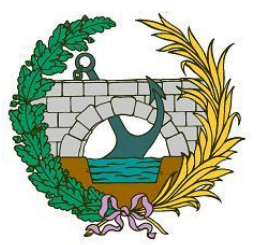

E.T.S. Ingeniería de Caminos, Canales y Puertos de Granada

\title{
ENSAYO DE UN MODELO MICROMECÁNICO PARA EL ESTUDIO DEL COMPORTAMIENTO DE MEZCLAS BITUMINOSAS
}

\section{Máster en Estructuras}

$2013 / 2014$

Autor:

Ana Jiménez del Barco Carrión Ingeniero de Caminos, Canales y Puertos

Tutores:

Dr. Rafael Gallego Sevilla

Dr. Fernando Moreno Navarro 



\section{AGRADECIMIENTOS}

La realización de este Trabajo Fin de Máster no habría sido posible sin la participación, ayuda y apoyo de diversas personas que han colaborado de una forma u otra en su desarrollo $y$ resultado final. Así pues, agradecer en primer lugar a mis tutores, D. Rafael Gallego Sevilla y D. Fernando Moreno Navarro, por su tutela y dedicación durante la realización del trabajo que se presenta.

En segundar lugar, agradecer a todos los miembros del Laboratorio de Ingeniería de la Construcción: a su directora y subdirector, Dạ. Mạ del Carmen Rubio y D. Germán Martínez, y a todos los compañeros, Miguel del Sol, Miguel Pérez, Jesús Martín, Gema García y Jaime García, por su constante colaboración, apoyo y compañerismo.

Agradecer también a la Escuela Técnica Superior de Ingeniería de Caminos, Canales y Puertos de la Universidad de Granada, por brindar sus instalaciones para la realización del Máster en Estructuras, y en particular, para el trabajo que se presenta.

Por último, agradecer a modo personal a mis familiares y amigos, por el incansable apoyo recibido durante la realización de este trabajo. 



\section{AUTORIZACIÓN}

D.

Profesor del departamento de.

de la Universidad de Granada, como director del Trabajo Fin de Máster de

D.

Informa:

Que el presente trabajo, titulado:

Ha sido realizado y redactado por el mencionado alumno bajo nuestra dirección, y con esta fecha autorizo a su presentación.

Granada, a ......de de $20 \ldots .$.

Fdo. 

Los abajo firmantes autorizan a que la presente copia de Trabajo Fin de Máster se ubique en la Biblioteca del Centro y/o departamento para ser libremente consultada por las personas que lo deseen.

Granada, a ......de .............. de $20 \ldots . .$.

(Firmas y números de DNI / NIE del alumno y de los tutores) 



\section{Informe de valoración del proyecto}

El tribunal constituido para la evaluación del Trabajo Fin de Máster titulado:

Realizado por el alumno:

Y dirigido por el tutor:

Ha resuelto la calificación de:

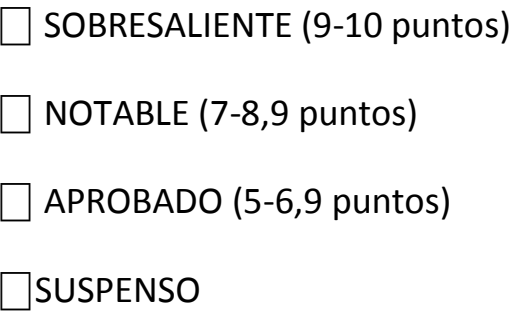

Con la nota ${ }^{1}: \quad$ puntos.

El Presidente:

El Secretario:

El Vocal:

Granada, a ......de de $20 \ldots . .$.

\footnotetext{
${ }^{1}$ Solamente con un decimal.
} 



\section{RESUMEN}

\section{ENSAYO DE UN MODELO MICROMECÁNICO PARA EL ESTUDIO DEL COMPORTAMIENTO DE MEZCLAS BITUMINOSAS}

La mayoría de las investigaciones sobre el diseño de firmes de mezclas bituminosas se basan en ensayos de laboratorio que determinan las propiedades mecánicas de las mismas intentando reproducir las condiciones de fabricación de la mezcla en planta, su puesta en obra y las acciones que sufrirá durante su vida de servicio.

Son muchas las variables que intervienen en el diseño de una mezcla bituminosa: tipo de árido, tamaño, tipo de ligante, contenido de huecos, etc., por lo que la realización de ensayos de laboratorio que abarquen todas ellas supone un consumo de material y tiempo muy elevados. Además, los materiales que componen las mezclas, áridos (provenientes de cantera) y betún (subproducto del petróleo), son recursos agotables que conllevan el deterioro del medio ambiente y un alto gasto económico. La posibilidad de predecir propiedades fundamentales de las mezclas bituminosas mediante modelos micromecánicos es esencial para suplir o reducir la necesidad de realizar ensayos de laboratorio. Asimismo, la simulación de las mezclas mediante estos modelos proporciona un mejor conocimiento del funcionamiento de la estructura interna de la mezcla.

El Trabajo Fin de Máster que se presenta ensaya teóricamente el Método de los Elementos Discretos para modelizar el comportamiento mecánico de mezclas bituminosas y relacionar las propiedades del modelo con las variables que intervienen en el diseño de mezclas. En particular, esta investigación se centra en el tamaño de árido, la naturaleza del mismo y el tiempo de aplicación de la carga.

Con este propósito, se ha generado un modelo $3 \mathrm{D}$ en el que se reproducen las propiedades volumétricas de las mezclas y se simula un ensayo de compresión uniaxial. Mediante la variación de las propiedades del modelo se obtienen resultados que se correlacionan con los datos de laboratorio. Dentro del rango de estudio del presente trabajo, se ha encontrado que el aumento del tamaño de árido no influye significativamente en las propiedades de las mezclas, pero sí en la rigidez de los contactos del modelo. Por el contrario, la naturaleza del árido y el tiempo de aplicación de la carga afectan tanto al comportamiento de la mezcla en laboratorio como a la rigidez de los contactos del modelo.

Palabras clave: mezcla bituminosa; modelización; método de los elementos discretos; micromecánica 



\section{ABSTRACT \\ MICROMECHANICAL APPROACH FOR THE STUDY OF BITUMINOUS MIXTURES BEHAVIOUR}

Most research in pavement design is based on laboratory tests that obtain mechanical properties of asphalt mixtures through the reproduction of their manufacturing, construction process and loading during their service life.

There are so many variables participating on asphalt mixtures design: aggregate type, aggregate size, binder type, voids, etc. Therefore, undertaking laboratory tests in order to evaluate all of those variables supposes a high consumption of material and time. In addition, asphalt mixtures materials come from finite natural resources whose exploitation implies great environmental and economic costs. Micromechanical models can predict fundamental material properties of bituminous mixtures based upon the properties of individual constituents such as the mastic and aggregate. Consequently, micromechanical modeling has tremendous potential benefits in the field of asphalt technology to reduce or eliminate costly tests to characterize asphalt mixtures for design and control of these materials. Furthermore, the models can provide tremendous insight towards understanding the mechanical behavior of complex, discontinuous media such as asphalt mixtures.

This final dissertation uses the Discrete Element Method to model the mechanical behavior of asphalt mixtures and to relate model properties to variables affecting bituminous mixtures design. Particularly, aggregate nature and size and loading time effects are evaluated.

To this end, a 3D model which is able to reproduce volumetric properties of asphalt mixes has been created. In order to evaluate model properties a uniaxial compression test was simulated. Through the variation of those properties, the model was fitted to laboratory results. In conclusion, it has been found that although results from laboratory mixtures are not significantly affected by aggregate size, model contacts have to be stiffer for larger aggregate sizes. Conversely, both, mixture and model behavior are affected by aggregate nature and loading time.

Keywords: asphalt mixture; modelling; Discrete Element Method; micromechanics 



\section{ÍNDICE}

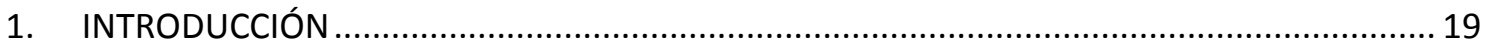

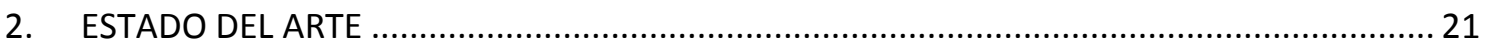

2.1. Descripción y fabricación de una mezcla bituminosa .................................................. 21

2.2. Comportamiento de mezclas bituminosas.................................................................. 23

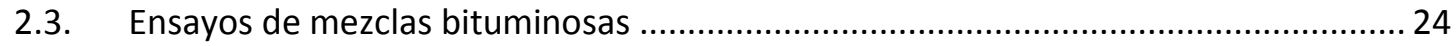

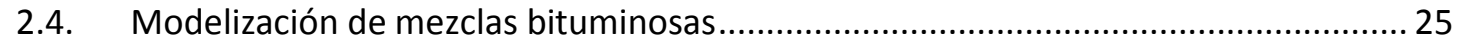

2.4.1. Modelización de mezclas bituminosas mediante el Método de los Elementos

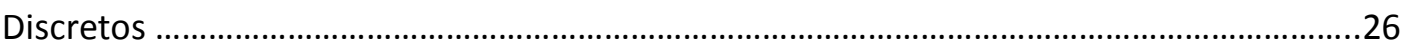

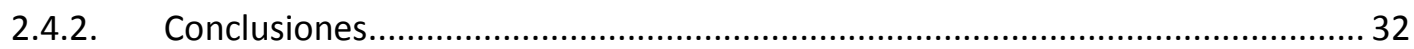

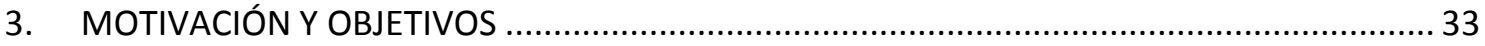

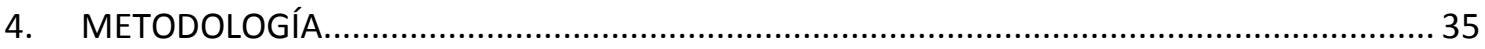

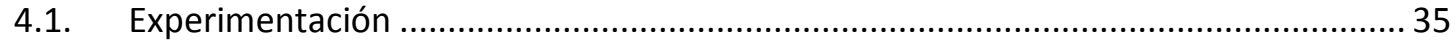

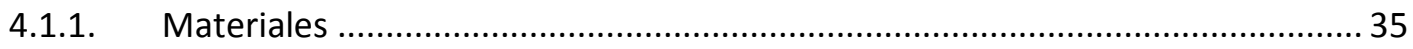

4.1.2. Diseño y fabricación experimental de las mezclas................................................. 36

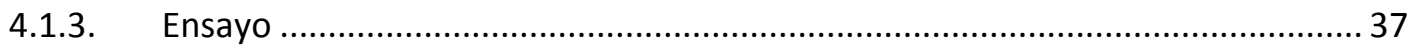

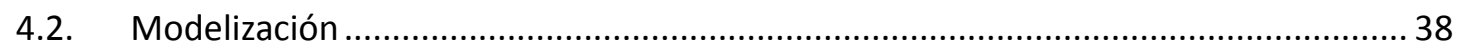

4.2.1. Introducción a "Particle Flow Code in Three Dimensions" (PFC3D) .................... 38

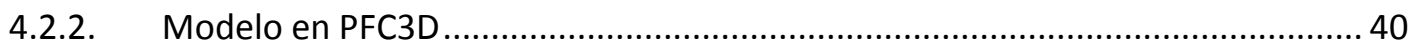

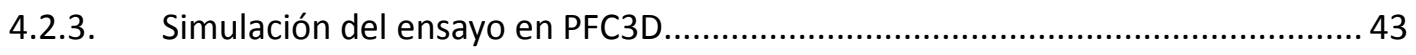

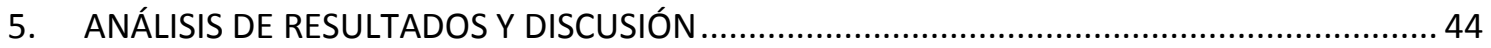

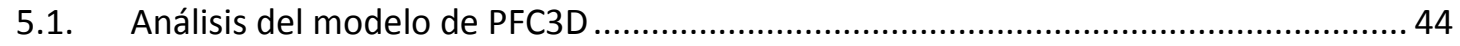

5.2. Análisis de la simulación del ensayo en PFC3D ..........................................................46

5.3. Comportamiento de las mezclas ensayadas en laboratorio ....................................... 47

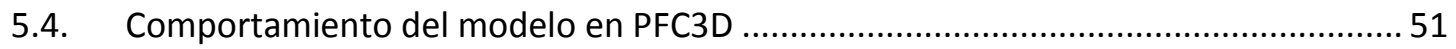

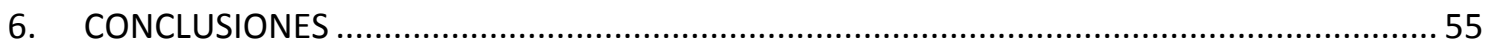

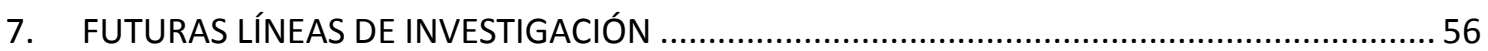

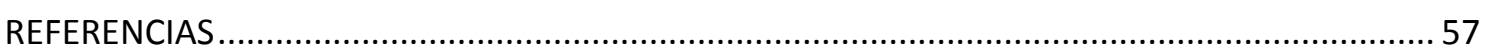

ANEXO I: Generación de la geometría y del conjunto de partículas............................................ 60

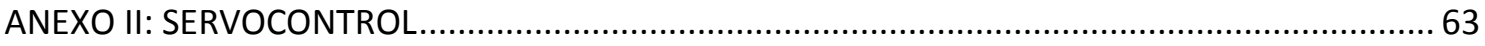

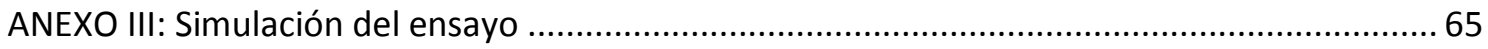


Ensayo de un modelo micro-mecánico para el estudio del comportamiento de mezclas

bituminosas 


\section{LISTA DE FIGURAS}

Figura 1. Estructura interna de una mezcla bituminosa.

Figura 2. a) Preparación de materiales para la fabricación de una mezcla bituminosa (Laboratorio de Ingeniería de la Construcción de la Universidad de Granada); b) Fabricación de la mezcla en amasadora (Laboratorio de Ingeniería de la Construcción de la Universidad de Granada) 21 Figura 3. Métodos de compactación de mezclas bituminosas en laboratorio (Laboratorio de Ingeniería de la Construcción de la Universidad de Granada): a) Compactador de impactos; b) Compactador de placas; c) Compactador vibratorio; d) Compactador giratorio. .22 Figura 4. Comportamiento elástico, viscoso y visco-elástico ideal de un material. a) Condiciones de carga y descarga; b) comportamiento puramente elástico; c) comportamiento puramente viscoso; d) comportamiento visco-elástico. (Adaptación de Abbas, 2004).

Figura 5. Curva típica obtenida en un ensayo uniaxial a deformación controlada (Adaptación de Taherkani, 2006)

Figura 6. Comportamiento visco-elástico con carga dinámica......

Figura 7. Modelización de mezclas bituminosas según los elementos de Maxwell, Burger y Kelvin-Voigt. (Chang y Meegoda, 1997)

Figura 8. Modelización en 3D a partir de imágenes en 2D. (You et al., 2008)...........................................28

Figura 9. Mezcla idealizada modelada en PFC3D. (Collop et al., 2004) .......................................................29

Figura 10. Probeta de mezcla bituminosa en PFC3D con una granulometría real. (Cai, 2013) .................29

Figura 11. Probetas cilíndricas de ensayo a tracción indirecta. a) Árido de tamaño pequeño, capas delgadas de betún; b) árido de tamaño grande, capas gruesas de betún. (Abbas, 2004) .........................30

Figura 12. Simulación de un ensayo de rodadura con DEM en PFC3D. (Liu, 2011)..................................31

Figura 13. Simulación de una probeta de mezcla bituminosa en PFC3D. (Yu y Shen, 2013).....................31 Figura 14. Probetas con áridos de diferente tamaño y naturaleza: a) Caliza 2-4 mm; b) Caliza 4-6 mm; c)

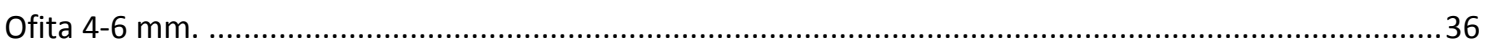

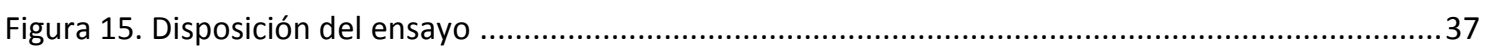

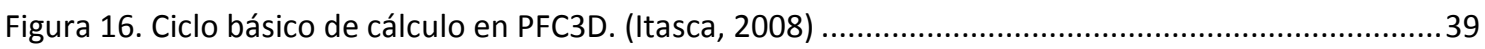

Figura 17. Detalle de las fuerzas que intervienen en el contacto entre dos partículas. (Adaptación de You

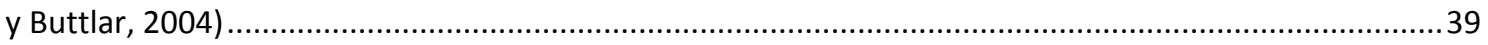

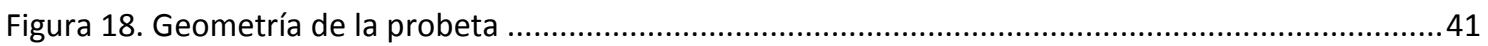

Figura 19. Ejemplo de generación de partículas ...................................................................................4 41

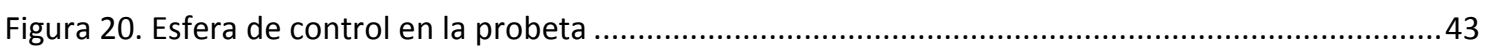

Figura 21. Configuración para el comienzo del ensayo ...................................................................43

Figura22. Modelos de las tres mezclas de laboratorio: a) árido calizo 2-4 mm; b) árido calizo 4-6 mm; c)

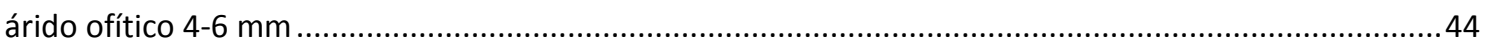

Figura 23. Control del número medio de contactos por partícula: a) árido calizo 2-4 $\mathrm{mm}$; b) árido calizo 4-6 mm; c) árido ofítico 4-6 mm.................................................................................................45 Figura 24. Desplazamiento de: a) actuador en el ensayo de laboratorio en el test 1 ; b) plato inferior en la

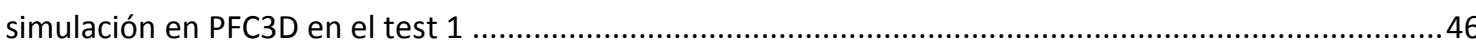
Figura 25. Tensión-deformación test 1: a) mezcla de laboratorio árido calizo 2-4 mm; b) mezcla de laboratorio árido calizo 4-6 mm; c) mezcla de laboratorio ofítico 4-6 mm..........................................48 Figura 26. Tensión-deformación test 2: a)mezcla de laboratorio árido calizo 2-4 mm; b) mezcla de laboratorio árido calizo 4-6 mm; c) mezcla de laboratorio ofítico 4-6 mm ...........................................49 Figura 27. Tensión-deformación test 3: a) mezcla de laboratorio árido calizo 2-4 mm; b) mezcla de laboratorio árido calizo 4-6 mm; c) mezcla de laboratorio ofítico 4-6 mm.........................................50 Figura 28. Obtención del módulo de Young en el modelo ...............................................................51 Figura 29. Módulo de Young con distinta rigidez de partículas para la mezcla de árido calizo 2-4 mm ....51 Figura 30. Módulo de Young según el tamaño de las partículas ........................................................52 
Figura 31. Módulo de Young según la naturaleza de las partículas ......................................................52

Figura 32. Rigidez normal de las partículas en función de la velocidad de ensayo ...................................53

Figura 33. Comportamiento del modelo y de la mezcla de árido calizo 4-6 mm en el test 1 ...................54

Figura 34. Relación entre el módulo en ensayos de laboratorio y simulaciones .....................................54

\section{LISTA DE TABLAS}

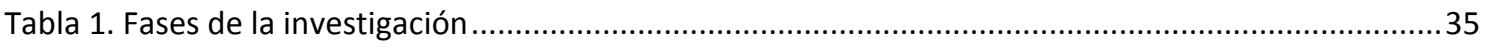

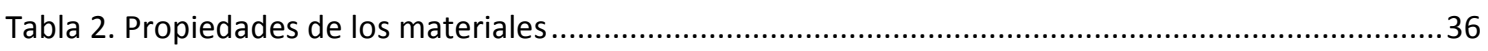

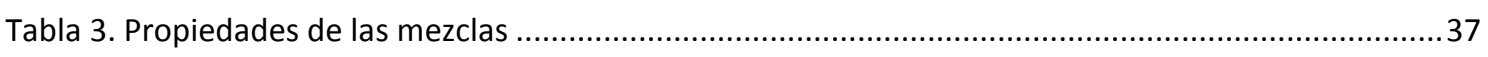

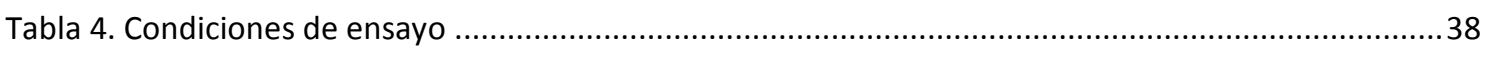

Tabla 5. Propiedades iniciales de las partículas del modelo ( Wu, 2009) ................................................42

Tabla 6.Relación entre la fuerza máxima en las partículas y en los contactos ........................................46 


\section{INTRODUCCIÓN}

El objetivo final del estudio de mezclas bituminosas para su utilización en firmes de carretera es la obtención de un material sostenible, económico y resistente a la acción del tráfico y acciones climáticas a las que estará sometido durante su vida de servicio.

El comportamiento de una mezcla bituminosa está condicionado por sus componentes (áridos, fíller y betún) y la interacción que se produce entre ellos durante el proceso de fabricación, que determinará la estructura interna final de la mezcla (empaquetamiento de los áridos, distribución de huecos, etc.). La comprensión de esta micro-estructura es fundamental para profundizar en el comportamiento de mezclas bituminosas.

La mayoría de las investigaciones sobre el diseño de firmes se basan en ensayos de laboratorio que determinan las propiedades mecánicas de mezclas bituminosas intentando reproducir las condiciones de fabricación de la mezcla en planta, su puesta en obra y las acciones que sufrirá durante su vida de servicio. Sin embargo, este tipo de investigación supone un elevado consumo de material y tiempo, ya que la mayoría de los ensayos son destructivos e impiden la reutilización de material, y además necesitan de atención continua y mano de obra. Por ello y dado el gran número de variables que influyen en la misma, a nivel de laboratorio se hace complicado y costoso conocer cómo afectan al comportamiento mecánico de la mezcla bituminosa.

Por estos motivos, en los últimos 20 años, la modelización y caracterización de mezclas bituminosas a través de métodos de cálculo (método de los elementos finitos, método de los elementos de contorno, modelos de celosías, método de los elementos discretos, etc.) ha ido adquiriendo cada vez más importancia. La caracterización de mezclas bituminosas mediante modelos micro-mecánicos permite la predicción de las propiedades fundamentales de la misma reduciendo o eliminando dichos consumos de material y tiempo, ya que pueden suponer la eliminación de variables de estudio en laboratorio. Además, dada su capacidad para estudiar la micro-estructura de los materiales, estos modelos ayudan a comprender mejor el comportamiento de materiales compuestos y discontinuos como son las mezclas asfálticas. Así, diversas investigaciones se han centrado en el uso de modelos micro-mecánicos con diferentes enfoques para predecir el comportamiento de mezclas asfálticas y másticos (fíller+betún). De entre los distintos modelos destacan los basados en el Método de los Elementos Finitos (FEM - Finite Element Method) y Método de los Elementos Discretos (DEM - Discrete Element Method).

El Trabajo Fin de Máster que se presenta ensaya teóricamente el Método de los Elementos Discretos para modelizar, mediante la simulación de un ensayo, el comportamiento de mezclas bituminosas.

Para ello, en el apartado 2 del mismo se describe la fabricación, el comportamiento y los ensayos de mezclas bituminosas, y se lleva a cabo una revisión bibliográfica de la modelización de las mismas mediante el Método de los Elementos Discretos. En el apartado 3, se expone la motivación y los objetivos del trabajo. En el apartado 4, se presenta la metodología seguida durante la realización del mismo. El apartado 5 presenta 
Ensayo de un modelo micro-mecánico para el estudio del comportamiento de mezclas

bituminosas

y discute los resultados obtenidos. Por último, en los apartados 6 y 7 se exponen las conclusiones y futuras líneas de investigación. 


\section{ESTADO DEL ARTE}

\subsection{Descripción y fabricación de una mezcla bituminosa}

Una mezcla bituminosa es un material compuesto por áridos, fíller, huecos de aire y betún(Figura 1). Durante la fabricación y compactación de la mezcla, áridos, fíller y betún interaccionan, creando contactos entre ellos y generando una estructura interna compleja capaz de resistir cargas de tráfico y condiciones climáticas diversas.

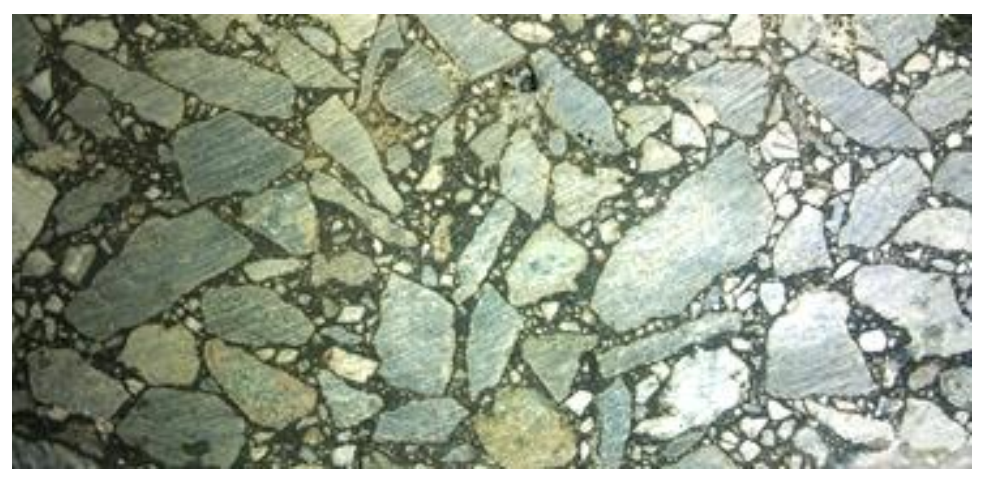

Figura 1. Estructura interna de una mezcla bituminosa

En los laboratorios de mezclas bituminosas se diseñan, fabrican y compactan mezclas simulando el proceso que se sigue en las plantas de fabricación y su compactación posterior en obra.

Para ello, el primer paso es diseñar la dosificación de la mezcla en la que se determinan la granulometría de la misma y el contenido de betún que poseerá. Una vez diseñada, los áridos, fíller y betún se calientan en una estufa (Figura 2a)) hasta alcanzar la temperatura deseada para que la mezcla se fabrique correctamente (en torno a los $150^{\circ} \mathrm{C}$ para mezclas bituminosas calientes). A continuación, los materiales se introducen en una amasadora (Figura $2 \mathrm{~b}$ )), en la que se mantiene la temperatura de los mismos y se asegura que los componentes se mezclan de forma adecuada.

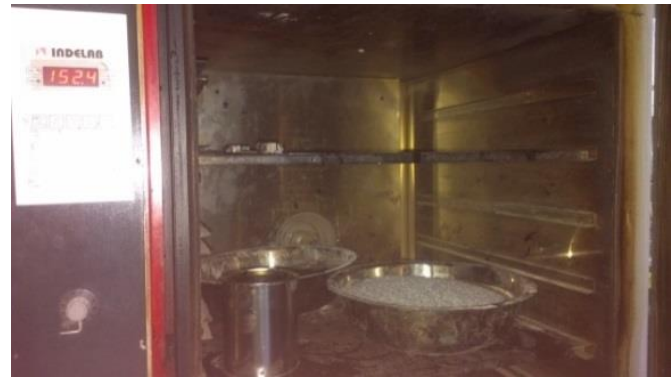

a)

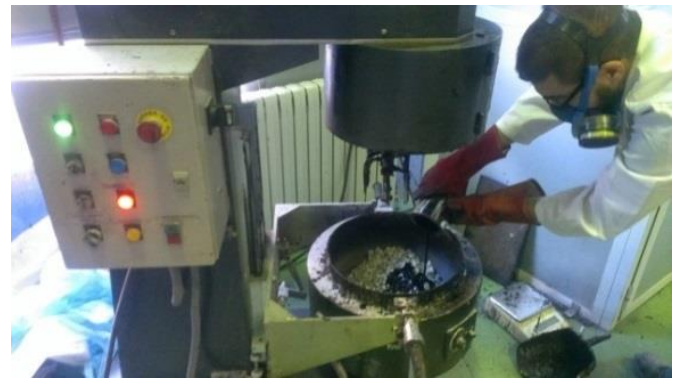

b)

Figura 2. a) Preparación de materiales para la fabricación de una mezcla bituminosa (Laboratorio de Ingeniería de la Construcción de la Universidad de Granada); b) Fabricación de la mezcla en amasadora (Laboratorio de Ingeniería de la Construcción de la Universidad de Granada)

Por último, se lleva a cabo la compactación de la mezcla. El principal objetivo de la compactación es conseguir un buen empaquetamiento de los áridos, así como una distribución uniforme del ligante y de los huecos, de forma que se asegure la existencia de 
cohesión árido-ligante y la estabilidad de la mezcla (Hartman et al., 2001). Además, cuando se trata de compactación en laboratorio, el propósito final será procurar una mezcla cuyas características sean lo más similares posibles a las de la mezcla compactada en obra (Swiertz et al., 2010). Con esta intención existen hoy en día diferentes métodos de compactación en laboratorio entre los que destacan: la compactación por impactos, por amasado, vibratoria y giratoria (Figura 3). La elección del método de compactación es un paso crítico en el proceso de fabricación de una mezcla bituminosa. Su importancia se atribuye a las diferentes estructuras internas (distribución de áridos y la asociada distribución de huecos (Massad et al., 1999)) que generan los distintos métodos de compactación, la cual influirá significativamente en el comportamiento posterior de la mezcla.

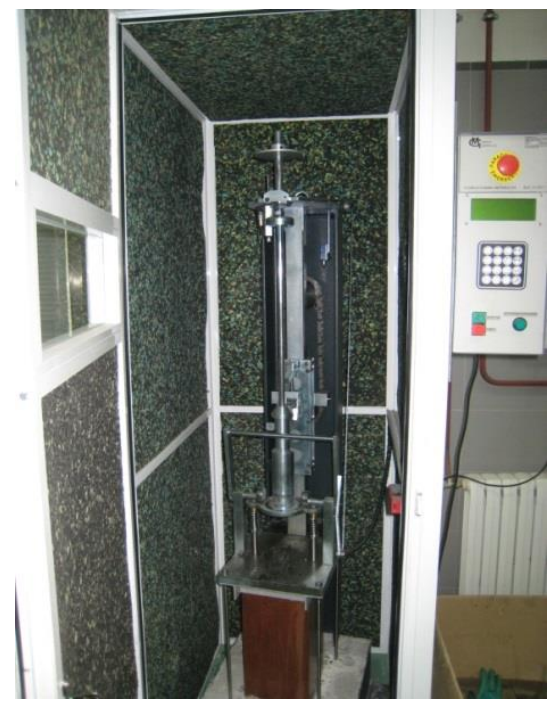

a)

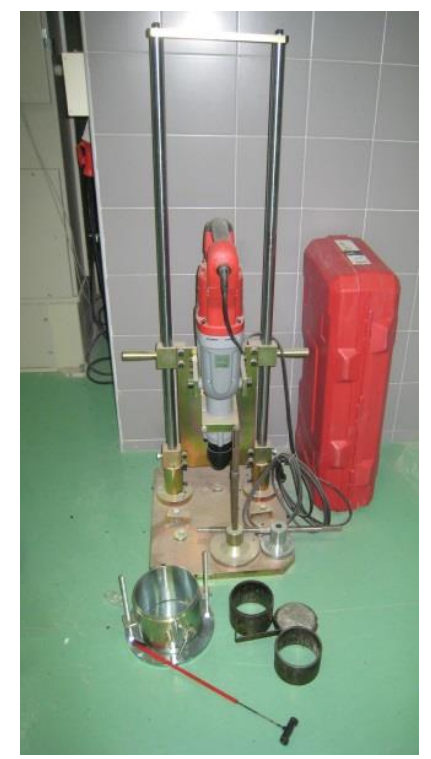

c)

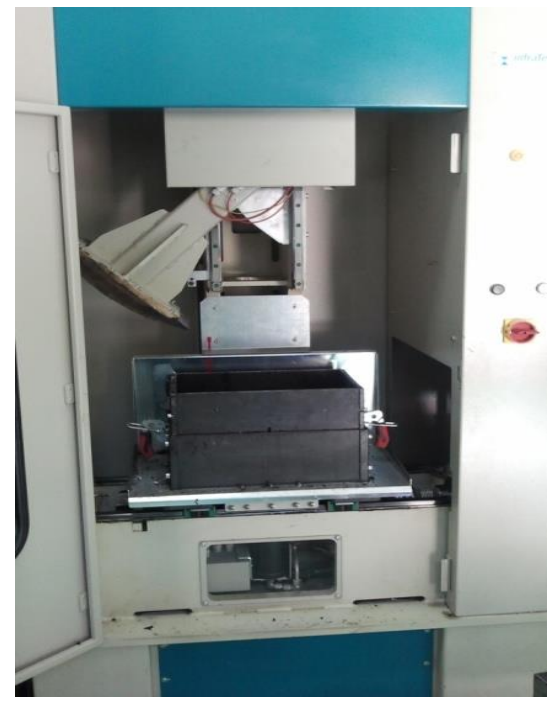

b)

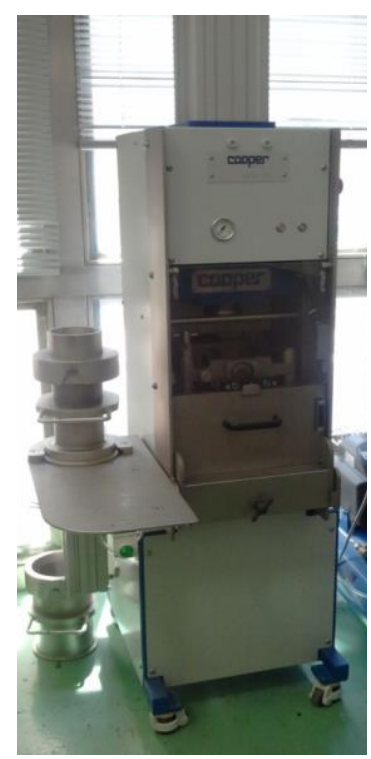

d)

Figura 3. Métodos de compactación de mezclas bituminosas en laboratorio (Laboratorio de Ingeniería de la Construcción de la Universidad de Granada): a) Compactador de impactos; b) Compactador de placas; c) Compactador vibratorio; d) Compactador giratorio 


\subsection{Comportamiento de mezclas bituminosas}

Cuando un material se somete a cualquier excitación durante un tiempo, en él se produce un reordenamiento interno de partículas como respuesta a la misma. Los materiales cuya respuesta no depende del tiempo de aplicación de la carga se conocen como materiales elásticos y son capaces de recuperar cualquier deformación que se le aplique.

Por otro lado, si la respuesta exhibe una dependencia del tiempo, el material se denominará viscoso (Schapery, 1974) y no recuperará la deformación que ha sufrido cuando cese el esfuerzo aplicado.

Los ligantes bituminosos presentan un punto intermedio entre ambos comportamientos, elástico y viscoso, y por tanto son conocidos como materiales visco-elásticos. Estos materiales presentan deformaciones crecientes frente a una carga constante aplicada durante un periodo de tiempo y relajación de tensiones bajo deformaciones constantes (Abbas, 2004). Además, cuando cese el esfuerzo al que se han sometido, recuperarán sólo una parte de la deformación que han sufrido.

Las diferencias entre los tres comportamientos pueden ilustrarse con un ensayo en el que se aplica una carga, se mantiene constante durante un tiempo y se retira. Dichas diferencias se representan en la Figura 4.
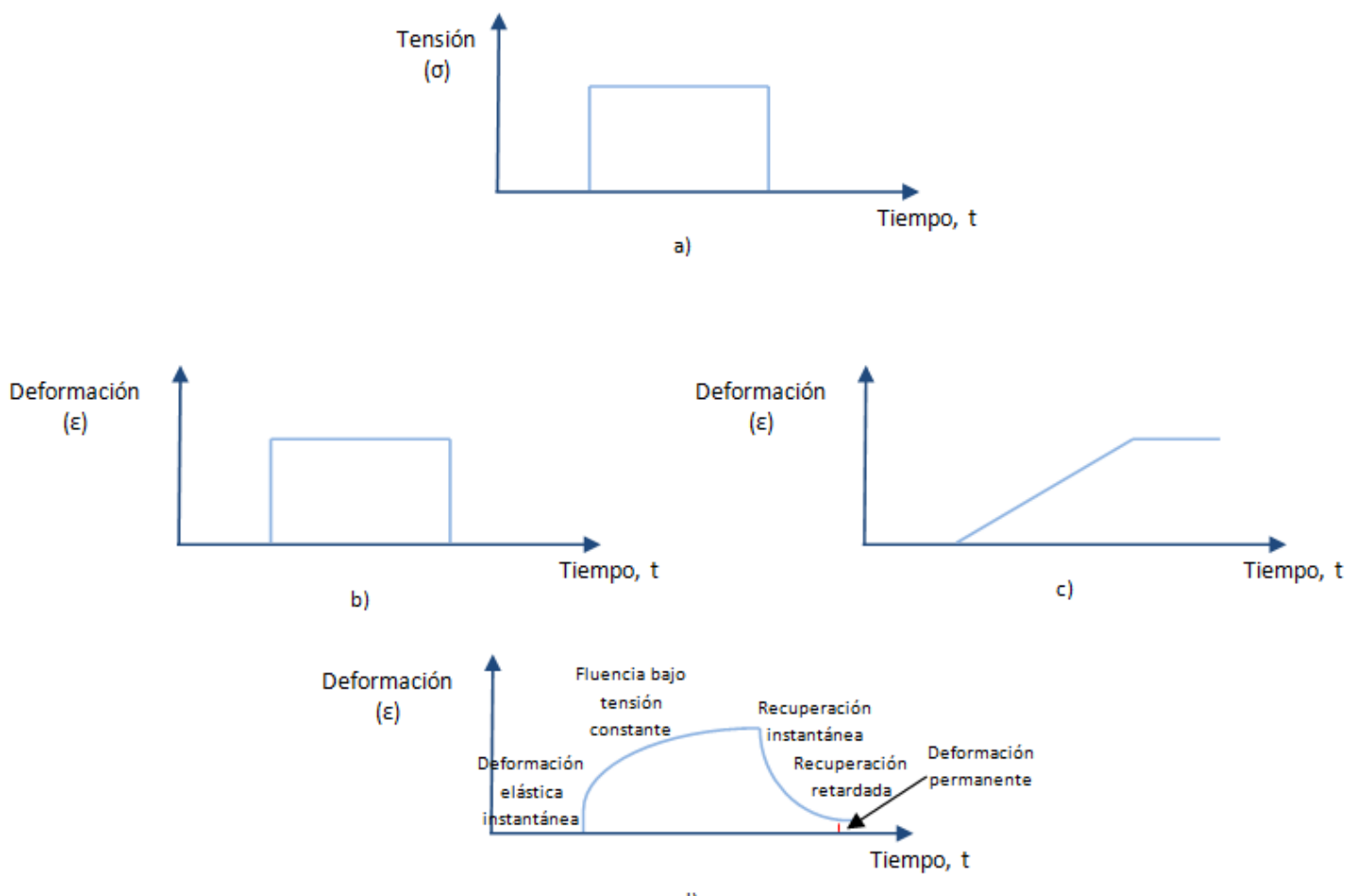

d)

Figura 4. Comportamiento elástico, viscoso y visco-elástico ideal de un material. a) Condiciones de carga y descarga; b) comportamiento puramente elástico; c) comportamiento puramente viscoso; d) comportamiento visco-elástico. (Adaptación de Abbas, 2004)

Así, el carácter visco-elástico de los ligantes bituminosos otorga a la mezcla un comportamiento del mismo tipo. 
Además, el tipo de árido, tipo de fíller, granulometría, tipo de betún y contenido de éste, método de compactación y temperatura de fabricación de la mezcla condicionarán la respuesta final de la misma (Massad et al., 1999).

Por último, el comportamiento de las mezclas asfálticas también depende de la temperatura a la que se encuentren. A bajas temperaturas, el betún y por tanto la mezcla, tiende a un comportamiento elástico, y a medida que ésta aumenta va adquiriendo más viscosidad (Polacco et. al, 2003). Realizando ensayos a distintas temperaturas es posible caracterizar la dependencia de la temperatura del comportamiento de la mezcla.

\section{3. $\quad$ Ensayos de mezclas bituminosas}

En la actualidad existen numerosos ensayos para caracterizar el comportamiento de las mezclas bituminosas. Estos ensayos tienen como finalidad obtener determinados parámetros, como son el módulo de Young, el coeficiente de Poisson, el módulo dinámico y el ángulo de fase, entre otros, que serán utilizados para mejorar el diseño de mezclas bituminosas, ya que evalúan su comportamiento, y para el dimensionamiento de firmes. Los ensayos de mezclas bituminosas son por tanto esenciales para predecir su respuesta ante las cargas a las que estarán sometidas durante su vida de servicio. Es posible diferenciar entre ensayos estáticos y dinámicos.

Un ensayo estático consiste en la aplicación de una carga estática durante un periodo de tiempo. Un ejemplo de este tipo de ensayos es el ensayo de compresión uniaxial estático, tanto a tensión como a deformación controlada. En este ensayo, se coloca una probeta cilíndrica entre dos platos, de los cuales uno es fijo y otro móvil que actúa como aplicador de la carga. Durante el ensayo se aplica rápidamente un esfuerzo o una deformación vertical que se mantiene constante durante un intervalo de tiempo. En la Figura 5 se muestra una curva modelo obtenida con un ensayo de compresión uniaxial a deformación controlada. En ella se diferencian cuatro zonas: la primera zona en la que el comportamiento es lineal y elástico, la segunda zona de endurecimiento inelástico hasta un punto máximo (tercera zona), y la cuarta en la que se produce la relajación de tensiones.

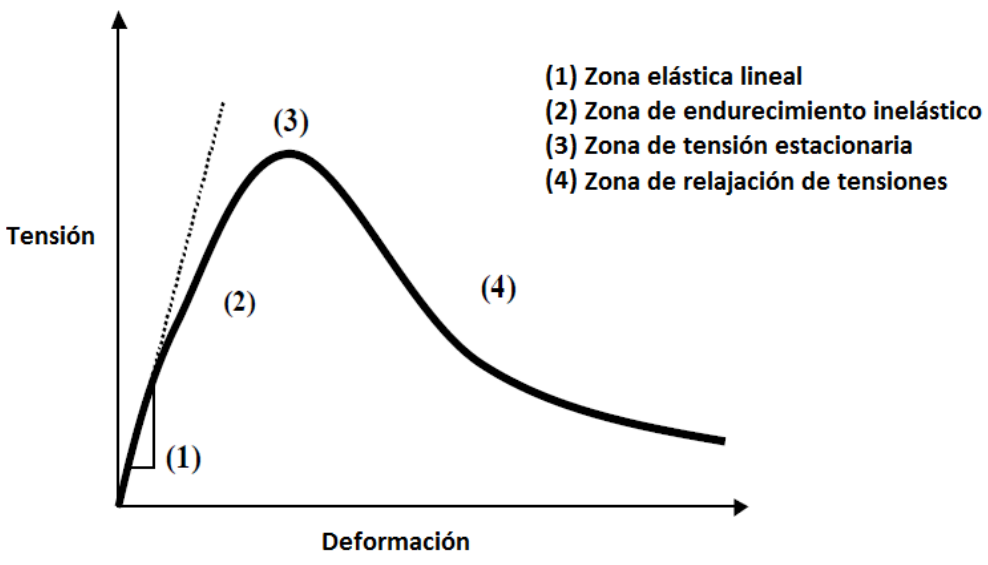

Figura 5. Curva típica obtenida en un ensayo uniaxial a deformación controlada (Adaptación de Taherkani, 2006) 
El módulo de Young se calcula mediante la relación de tensión-deformación al principio del ensayo, en la primera zona de la Figura 5. El coeficiente de Poisson (Ecuación 1) se define como el cociente entre la deformación radial y la axial en la zona elástica (Cai, 2013).

$$
v=-\frac{\varepsilon_{\text {radial }}}{\varepsilon_{\text {axial }}}
$$

Por otro lado, un ensayo dinámico consiste en la aplicación de cargas cíclicas a una frecuencia determinada. Una forma típica de aplicación de estas cargas es con funciones armónicas seno o coseno. En los ensayos se controlan la tensión o la deformación aplicadas y se mide el valor no controlado. El módulo dinámico se obtiene como la relación entre tensión y deformación máximas $(E)$ y dependerá de la frecuencia de aplicación de la carga $(\omega)$ (Ecuación 2). Además, dado el carácter visco-elástico de la mezcla bituminosa, la tensión y deformación se desfasan en el tiempo, este desfase se conoce como ángulo de fase $(\varphi)$. En la Figura 6 se ven representados estos parámetros.

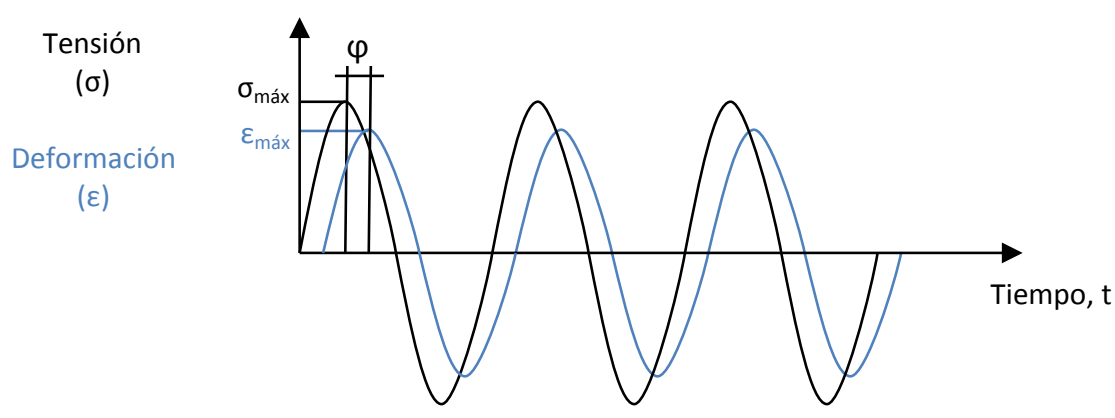

Figura 6. Comportamiento visco-elástico con carga dinámica

$$
E(\omega)=\frac{\sigma_{\operatorname{máx}}}{\varepsilon_{\operatorname{máx}}}
$$

\subsection{Modelización de mezclas bituminosas}

Los ensayos de laboratorio para el estudio del comportamiento mecánico de mezclas bituminosas suponen un consumo de material y tiempo muy elevados. La caracterización de mezclas bituminosas mediante modelos micro-mecánicos permite la predicción de las propiedades fundamentales de la misma reduciendo o eliminando dichos consumos de material y tiempo. Además, dada su capacidad para estudiar la micro-estructura de los materiales, estos modelos ayudan a comprender mejor el comportamiento de materiales compuestos y discontinuos como son las mezclas asfálticas (You y Buttlar, 2004). Por ello, durante los últimos 20 años la modelización de mezclas bituminosas ha ido adquiriendo cada vez más importancia.

En la literatura se encuentran diversos modelos para la caracterización de mezclas bituminosas, entre los que destacan: 
- Modelos de Elementos Finitos (FEM - Finite Element Method)

- Modelos Elementos Discretos (DEM - Discrete Element Method)

Estos dos modelos se han ido desarrollando en paralelo durante las últimas décadas. Por un lado, el potencial del Método de los Elementos Finitos para simular el comportamiento de mezclas bituminosas está hoy en día ampliamente reconocido (Dai y You, 2007).Sin embargo, a pesar de que permiten la modelización de geometrías de la micro-estructura de la mezcla muy detalladas, presentan dificultades para permitir la reestructuración entre partículas que se produce durante los ensayos, o simular deterioros en la misma como las roderas (Buttlar y You, 2001; Cai, 2013).

Por su parte, la caracterización de mezclas asfálticas mediante el Método de los Elementos Discretos lleva a cabo la modelización de la misma a nivel de partículas. Este hecho permite obtener un amplio conocimiento sobre la estructura interna de la mezcla ya que, además de implementar geometrías complejas, el método tiene la capacidad de simular los desplazamientos de partículas relativos que se producen durante los ensayos, y conseguir la propagación de grietas (Buttlar y You, 2001; Dondi et al., 2012). Las investigaciones llevadas a cabo utilizando el Método de los Elementos Discretos para la modelización de mezclas bituminosas se revisan en el siguiente apartado.

2.4.1. Modelización de mezclas bituminosas mediante el Método de los Elementos Discretos

El Método de los Elementos Discretos (DEM) fue introducido por Cundall (1971) para el estudio de problemas mecánicos en rocas. Este método es capaz de describir el comportamiento mecánico de materiales granulares mediante su modelización en discos (2D) o esferas (3D) cargadas y la determinación sucesiva de las fuerzas de contacto y desplazamientos entre las mismas.

Los primeros modelos de mezclas bituminosas en 2D usando DEM surgieron en los años 90 (Chang et al., 1993; Rottenburg et al., 1992). En ellos, las partículas se modelaban mediante discos unidos por un ligante viscoelástico. Estos modelos probaron la validez del DEM para simular el comportamiento de mezclas bituminosas con deformaciones permanentes (Cai, 2013). Para ello, Chang et al. 1993 utilizó elementos de Kelvin en la simulación del comportamiento viscoelástico del betún en el contacto entre partículas creando un modelo denominado ASBAL. Chang y Meegoda (1997) compararon el elemento de Kelvin, Maxwell y Burger para este propósito (Figura7), llegando a la conclusión de que el elemento de Burger era el más adecuado para la modelización del betún. Este elemento ha sido el utilizado desde entonces en la simulación de mezclas bituminosas mediante DEM. 

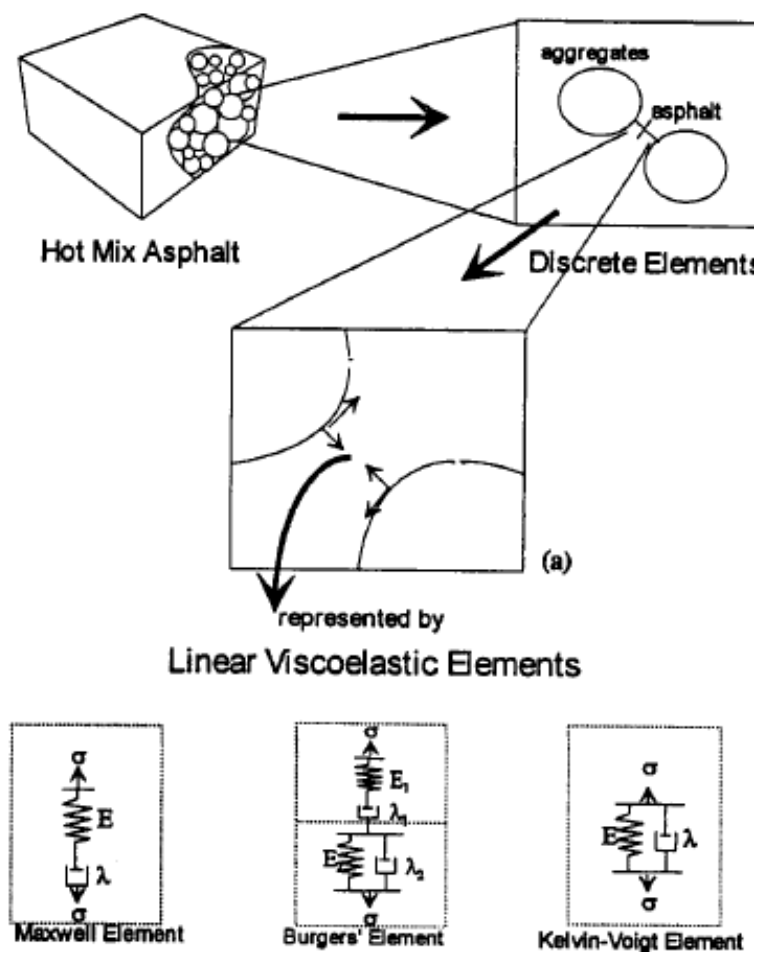

Figura 7. Modelización de mezclas bituminosas según los elementos de Maxwell, Burger y Kelvin-Voigt. (Chang y Meegoda, 1997)

Buttlar y You (2001) desarrollaron una extensión del DEM en 2D denominado MDEM (Microfabric Discrete Element Modelling), en el que utilizaban agrupaciones de elementos discretos muy pequeños para simular las distintas fases de la mezcla bituminosa. Este modelo tiene todas las ventajas del DEM, añadiendo la posibilidad de crear formas de partículas complejas similares a las de los áridos en la mezcla y permitir la propagación de grietas alrededor de los mismos o a través de ellos. Para ello utilizaron un programa de cálculo de elementos discretos denominado "Particle Flow Code in Two Dimensions" (PFC2D). Sin embargo, este modelo proporcionaba una rigidez a la mezcla inferior a la real.

Progresivas mejoras de este modelo consiguieron finalmente predecir el módulo complejo de una mezcla en ensayos de tracción-compresión en un rango de temperaturas y frecuencias de carga (You et al., 2004), el módulo complejo de cilindros huecos de mezcla sometidos a una presión interna (You et al., 2005), el módulo dinámico (You et al., 2006) y la rigidez en ensayos de fluencia de mezclas bituminosas (Dai et al., 2007). Los resultados de estos estudios demostraron una alta capacidad para predecir propiedades de las mezclas al compararse con resultados de laboratorio.

You et al. (2008) introdujeron la modelización en 3D con DEM de mezclas bituminosas para predecir el módulo dinámico. La modelización en 3D se llevó a cabo mediante la unión de imágenes en 2D (Figura 8). Para ello, utilizaron la extensión del programa de cálculo de elementos discretos PFC2D en 3D (PFC3D). Esta modelización se ajustaba mejor a los resultados experimentales que la modelización en 2D. 


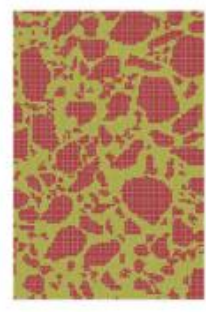

Model 1

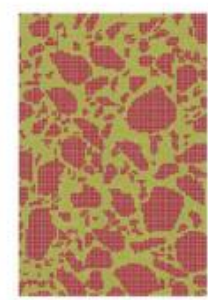

Model 3

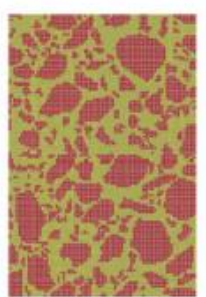

Model 2

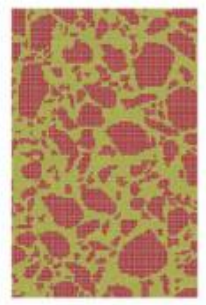

Model 4

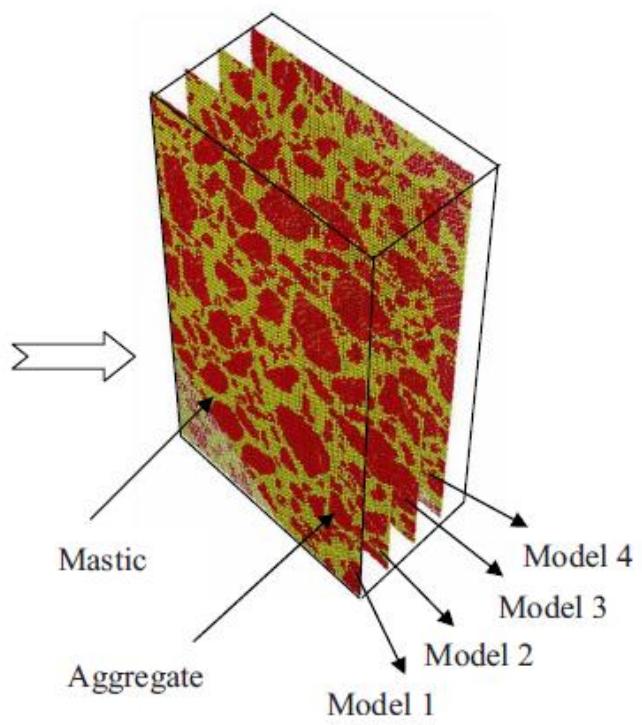

Model 1

Figura 8. Modelización en 3D a partir de imágenes en 2D. (You et al., 2008)

Collop et al. (2004) presentaron un modelo de DEM en 3D para simular el comportamiento de una mezcla idealizada con un tamaño único de partículas y betún en ensayos de compresión uniaxial y triaxial. Para ello, utilizaron el mismo programa de cálculo de elementos discretos que You et al. (2008), PFC3D. La Figura 9 representa la probeta idealizada de este modelo. En ella, el efecto del betún se simulaba a través las propiedades de los contactos entre partículas y estudiaba el efecto del número de partículas en los modelos.

Investigaciones posteriores en la misma línea (Lee, 2006) demostraron que el módulo de estas mezclas idealizadas dependía linealmente de la rigidez normal del contacto, y era independiente de la rigidez tangencial. Además, concluyeron que el módulo de Poisson del material modelado únicamente dependía del cociente entre la rigidez normal y tangencial de los contactos. La rigidez a compresión se simuló mediante un contacto elástico entre partículas, mientras que la rigidez a tracción y tangencial se simuló mediante un contacto viscoelástico con el modelo de Burger. La mezcla idealizada se dilataba a medida que el cociente entre la rigidez de compresión y tracción aumentaba como función del tiempo de carga. Todos los resultados fueron contrastados con trabajos experimentales. 


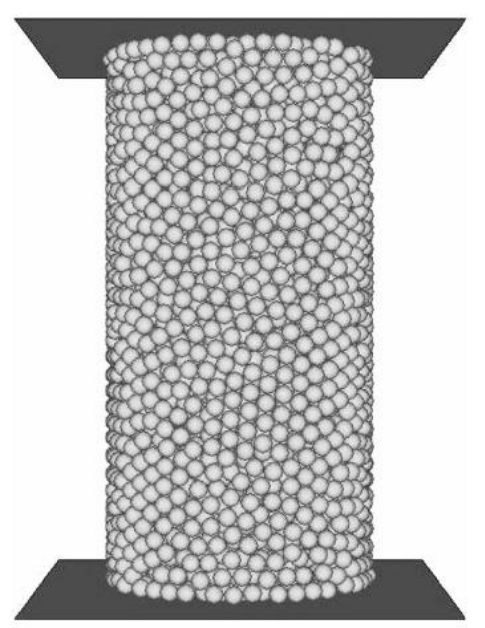

Figura 9. Mezcla idealizada modelada en PFC3D. (Collop et al., 2004)

Continuando con este modelo, Wu (2009) simuló la fisuración de la mezcla idealizada produciendo la rotura de la ligadura entre partículas adyacentes. Para permitir esta rotura creó las ligaduras como funciones del tiempo. En la comparación con datos experimentales obtuvo buenos resultados. Por último en esta línea de investigación de la Universidad de Nottingham, Cai (2013) rompe con la idealización de la mezcla introduciendo una granulometría real en la modelización en PFC3D (Figura 10). Cai (2013) utiliza modelos elásticos para estudiar la influencia del número de partículas y su distribución, la velocidad de carga y la rigidez normal y tangencial entre las partículas. En la simulación viscoelástica introduce una modificación del modelo de Burger que proporciona a las partículas resistencia a la torsión y al momento y además reduce el tiempo computacional de cálculo. Este modelo proporcionó buenos resultados en la comparación con ensayos de laboratorio presentándose así como una herramienta útil para la modelización de mezclas bituminosas.

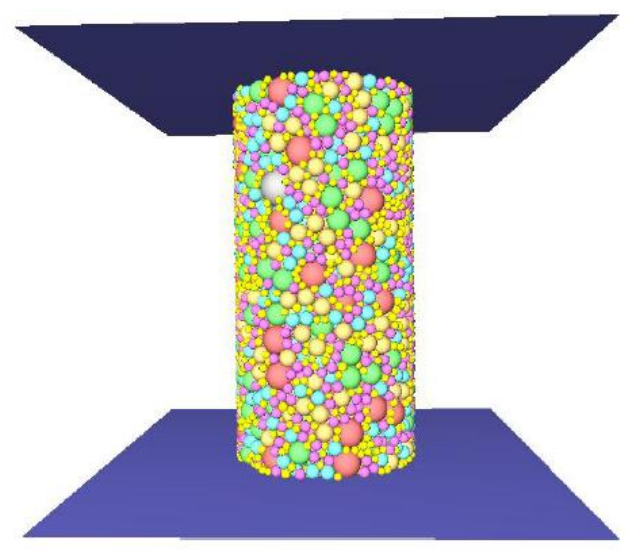

Figura 10. Probeta de mezcla bituminosa en PFC3D con una granulometría real. (Cai, 2013)

Abbas (2004) estudió el efecto de distintos fíllers en el mástico mediante la generación de modelos de DEM en 2D utilizando el programa PFC2D, que contenían diferentes porcentajes de partículas de distinta rigidez. Además, evaluó el efecto de la temperatura en los ligantes modificando las propiedades de las partículas. Los resultados se 
contrastaron con datos experimentales utilizando distintos tipos de fíller y diferentes concentraciones del mismo en el mástico. Por otro lado, estudió la respuesta viscoelástica de mezclas bituminosas a altas temperaturas y los mecanismos de fisuración a bajas temperaturas. En ellas asumió que los áridos son partículas rígidas. Los resultados se contrastaron con ensayos de laboratorio utilizando el mismo tipo de árido y nueve betunes distintos. También evaluó la influencia del espesor de la película de betún en ensayos a tracción indirecta (Figura 11). Para ello, introdujo tres tipos de contactos distintos: árido-árido, árido-ligante y ligante-ligante.

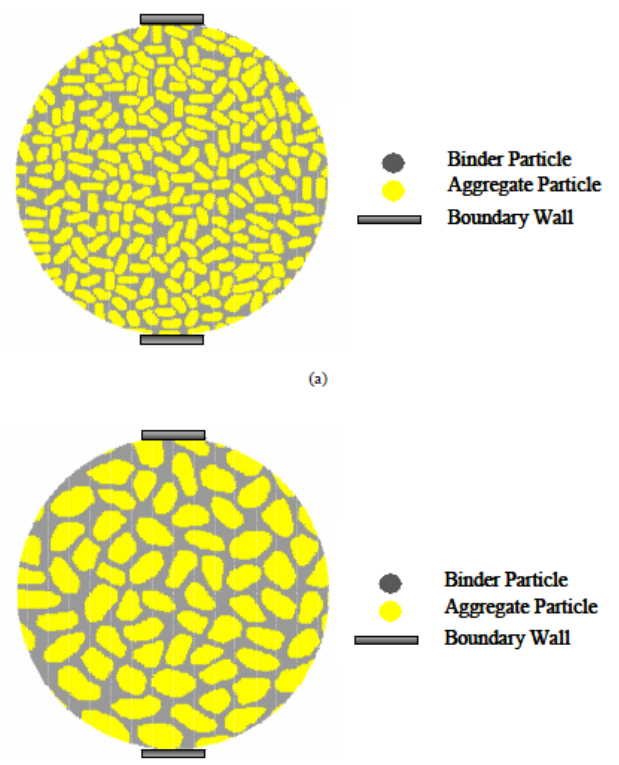

Figura 11. Probetas cilíndricas de ensayo a tracción indirecta. a) Árido de tamaño pequeño, capas delgadas de betún; b) árido de tamaño grande, capas gruesas de betún. (Abbas, 2004)

Liu (2011) utilizó tres enfoques para simular la microestructura de mezclas bituminosas en el programa PFC3D: modelos generados aleatoriamente, modelos idealizados y modelos basados en imágenes. Así, recomienda que los modelos basados en imágenes se utilicen para la predicción de las propiedades de la mezcla, mientras que los otros dos tan sólo sirvan para obtener una mejor comprensión del comportamiento de la microestructura de ésta. Utilizó un modelo viscoelástico para simular las interacciones de la microestructura de la mezcla bituminosa. Creó cuatro modelos constitutivos para modelizar los cuatro tipos de interacciones que concurren en una probeta de mezcla asfáltica. Cada uno de estos modelos constaba de tres partes: un modelo de rigidez, un modelo de ligadura y un modelo de deslizamiento. Además, utilizó tres técnicas distintas para reducir el tiempo computacional de cálculo en las simulaciones, consiguiendo disminuirlo de días a horas y de meses a días en simulaciones 3D. Concluyó que los modelos DEM pueden predecir con éxito el módulo dinámico, ángulos de fase y ensayos de fluencia en un amplio rango de frecuencias, temperaturas y períodos de tiempo. Por otro lado estudió la influencia de las características de los áridos en los ensayos de fluencia, obteniendo como resultado que éstas influyen notablemente en los mismos. Por último, analizó la interacción entre el pavimento y los vehículos simulando ensayos de rodadura (Figura 12). Concluyó que la 
aceleración y deceleración de las ruedas tiene un importante efecto en los contactos entre partículas.

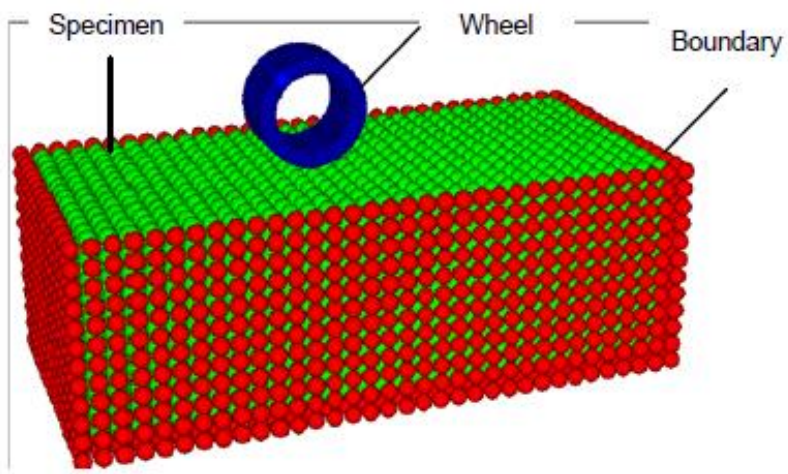

Figura 12. Simulación de un ensayo de rodadura con DEM en PFC3D. (Liu, 2011)

Dondi et al. (2012) presentaron la primera parte de un trabajo de dos etapas en el que estudian el efecto de la forma de las partículas y su distribución de tamaños en el empaquetamiento de los áridos mediante modelos de DEM en 3D con el programa de cálculo PFC3D. En esta primera fase analizan el efecto de la forma y la angularidad de las partículas en el empaquetamiento y estabilidad de materiales granulares. Para ello llevaron a cabo ensayos con esferas metálicas de distintos tamaños. Los resultados de ensayos triaxiales probaron que estas variables tienen una gran influencia en el comportamiento de los materiales granulares.

Yu y Shen (2013) crearon un modelo DEM con una microestructura compleja de agrupaciones de partículas que simulan la forma de los áridos y permite estudiar su influencia en las propiedades de la mezcla (Figura 13). En el contacto entre agrupaciones de partículas utilizan el elemento de Burger. Evaluaron el módulo complejo y ángulo de fase de las mezclas bituminosas obteniendo resultados que se ajustan a los datos experimentales.

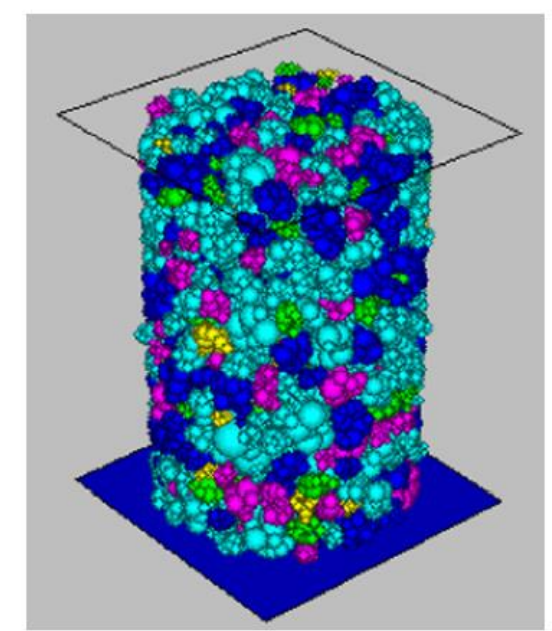

Figura 13. Simulación de una probeta de mezcla bituminosa en PFC3D. (Yu y Shen, 2013) 


\subsubsection{Conclusiones}

Tras la realización de la revisión bibliográfica sobre la utilización del Método de los Elementos Discretos en la modelización de mezclas bituminosas se pueden extraer las siguientes conclusiones:

- La modelización a través de modelos micromecánicos de mezclas bituminosas es hoy en día un paso importante hacia el ahorro de material y tiempo en la comprensión del comportamiento de estos materiales.

- Está ampliamente demostrada la validez de la utilización del Método de los Elementos Discretos para la modelización de mezclas bituminosas.

- La influencia de la velocidad de carga y temperatura sobre la rigidez de las partículas y distribución de las mismas es posible evaluarla mediante simulaciones elásticas.

En base a estas conclusiones, sería interesante desarrollar un modelo micromecánico con el Método de los Elementos Discretos capaz de evaluar cambios en las propiedades de mezclas bituminosas. Para ello, se habrá de conocer la relación entre las propiedades del modelo y de la mezcla bituminosa. 


\section{MOTIVACIÓN Y OBJETIVOS}

En ocasiones son muchas las variables que intervienen en el diseño de una mezcla bituminosa: tipo de árido, tamaño, tipo de ligante, contenido de huecos, etc., por lo que la realización de ensayos de laboratorio que abarquen todas ellas supone un consumo de material y tiempo muy elevados. Además, los materiales que componen las mezclas, áridos (provenientes de cantera) y betún (subproducto del petróleo), son recursos agotables que conllevan el deterioro del medio ambiente y un alto gasto económico. Así, es necesaria la búsqueda de herramientas que evalúen estas variables reduciendo el consumo de los mismos y de tiempo y que permitan descartar algunas de las variables como soluciones para el diseño de la mezcla.

La posibilidad de predecir propiedades fundamentales de las mezclas bituminosas mediante modelos micro-mecánicos que suplen o reducen la necesidad de realizar ensayos de laboratorio, supone un importante ahorro de material y tiempo. Además, la simulación de las mezclas mediante estos modelos proporciona un mejor conocimiento del funcionamiento de la estructura interna de la mezcla.

El Método de los Elementos Discretos se presenta hoy en día como uno de los más importantes y extendido en la modelización de mezclas bituminosas, habiéndose obtenido diversos avances en la misma durante los últimos 20 años. La utilización del programa "Particle Flow Code" en 2D o 3D destaca entre las distintas investigaciones revisadas en el estado del arte del presente trabajo.

En la actualidad, a pesar de conocer el comportamiento visco-elástico de las mezclas bituminosas, en el diseño de firmes de carreteras en España las mezclas se caracterizan en base al módulo de Young, coeficiente de Poisson y la vida hasta fatiga. A partir de estas propiedades de la mezcla bituminosa se calcula el espesor de capa requerido en el firme para soportar las cargas debidas al tráfico, en base a los fundamentos de la teoría multicapa de Boussinesq (1885) y Burmister (1962).

De esta forma, uniendo la importancia de la modelización mediante Elementos Discretos de mezclas bituminosas y del cálculo de parámetros elásticos en las mismas, surge la motivación de desarrollar un modelo micro-mecánico de Elementos Discretos en 3D utilizando el programa PFC3D con el que se puedan obtener dichos parámetros elásticos a partir de la simulación de ensayos. Este será el objetivo final de la investigación. Así, se podrían diseñar mezclas bituminosas en PFC3D realizando simulaciones con distintos tipos de áridos, tipos de betún, contenido de huecos, etc. obteniendo la mezcla bituminosa que cumpliese los requisitos necesarios, de modo que en laboratorio únicamente se contrastase dicho resultado.

Para la consecución de este objetivo final, se han definido dos etapas:

1. Modelización de una mezcla bituminosa sencilla para determinar el efecto de las distintas variables (tipos de áridos, tipos de betún, contenido de huecos, etc.) que 
afectan al comportamiento de mezclas bituminosas en las propiedades del modelo de Elementos Discretos en PFC3D.

2. Modelización de una mezcla bituminosa completa teniendo en cuenta las variables analizadas en la primera etapa.

El presente trabajo es el comienzo de la primera de estas etapas. En el mismo se han definido los siguientes objetivos específicos:

- Fabricación y ensayos de una mezcla bituminosa con diferentes tamaños de árido.

- Implementación de un modelo de dicha mezcla bituminosa en PFC3D.

- Simulación del ensayo real en PFC3D.

- Obtención de la relación entre las propiedades del modelo de PFC3D y el cambio del tamaño de árido, naturaleza de los mismos y el tiempo de aplicación de la carga en la mezcla bituminosa. 


\section{METODOLOGÍA}

En el comportamiento de las mezclas bituminosas influyen distintas variables como son:

- Naturaleza de los áridos y fíller

- Tamaño de los áridos

- Granulometría

- Tipo de betún

- Contenido de betún

- Densidad /contenido de huecos de la mezcla

- Tipo de compactación

- Tiempo de aplicación de la carga

- Temperatura

En el presente trabajo se centra en el estudio del efecto del tamaño de los áridos, la naturaleza de los mismos y tiempo de aplicación de la carga sobre las propiedades de un modelo de Elementos Discretos de mezcla bituminosa en PFC3D.

Para ello, se ha llevado a cabo una fase experimental en el Laboratorio de Ingeniería de la Construcción de la Universidad de Granada y una fase de modelización. Las etapas de cada una de estas fases se presentan en la Tabla 1.

Tabla 1. Fases de la investigación

\begin{tabular}{|c|c|}
\hline EXPERIMENTACIÓN & MODELIZACIÓN \\
\hline 1. Materiales & 1. Introducción a PFC3D \\
\hline $\begin{array}{l}\text { 2. Diseño y fabricación experimental } \\
\text { de las mezclas }\end{array}$ & $\begin{array}{l}\text { 2. Implementación del modelo en } \\
\text { PFC3D }\end{array}$ \\
\hline 3. Ensayos & 3. Simulación del ensayo en PFC3D \\
\hline
\end{tabular}

Concluidas estas fases, los resultados de laboratorio se ponen en común con los del modelo. A continuación se desarrollan en detalle cada una de las mismas.

\subsection{Experimentación}

\subsubsection{Materiales}

Para evaluar la influencia del tamaño del árido y de la naturaleza del mismo se utilizó una mezcla bituminosa sencilla con un tamaño de árido comprendido en un rango pequeño de variabilidad y un betún convencional. La ausencia de fíller permite observar de una forma más clara las propiedades de los contactos entre partículas, que posteriormente se modelarían en PFC3D. De esta forma, se fabricaron tres mezclas con el mismo betún y distinto tamaño y naturaleza del árido. Las propiedades de los materiales se presentan en la Tabla 2. 
Tabla 2. Propiedades de los materiales

\begin{tabular}{cccc}
\hline $\begin{array}{c}\text { Naturaleza del } \\
\text { árido }\end{array}$ & $\begin{array}{c}\text { Tamaño del árido } \\
(\mathrm{mm})\end{array}$ & $\begin{array}{c}\text { Densidad de los áridos }\left(\mathrm{Mg} / \mathrm{m}^{3}, \mathbf{N L T} \text { - }\right. \\
\mathbf{1 6 7 / 9 6 )}\end{array}$ & Tipo de betún \\
\hline Caliza & $2-4$ & 2,759 & $\begin{array}{c}\text { Convencional } \\
50 / 70\end{array}$ \\
Caliza & $4-6$ & 2,807 & $\begin{array}{c}\text { Convencional } \\
50 / 70\end{array}$ \\
Ofita & $4-6$ & 2,722 & $\begin{array}{c}\text { Convencional } \\
50 / 70\end{array}$ \\
\hline
\end{tabular}

\subsubsection{Diseño y fabricación experimental de las mezclas}

Para determinar el contenido de betún de las mezclas se realizaron pruebas experimentales en el Laboratorio de Ingeniería de la Construcción de la Universidad de Granada. El objetivo era obtener mezclas en las que los áridos quedasen cubiertos por una película fina de ligante que proporcionase propiedades a los contactos para posteriormente simularlos en PFC3D.

Para ello, se fabricaron mezclas con distintos contenidos de ligante hasta alcanzar dicho objetivo. En la Tabla 3 se muestran las propiedades finales de las mezclas con el contenido de betún seleccionado.

Por último, las mezclas se compactaron mediante el compactador de impactos (Figura 3 a)). Este método es el más utilizado en España y se encuentra recogido en la norma UNEEN 12697-30 (AENOR, 2013). La mezcla se compacta por medio de un peso deslizante que se deja caer desde una altura establecida un número determinado de veces sobre la base del martillo de compactación. El diámetro de las probetas compactadas es de 101,6 mm. Sobre las probetas compactadas mediante este equipo se llevan a cabo determinaciones volumétricas (densidad y huecos en mezcla). La Figura 14 presenta un ejemplo de las probetas fabricadas (parte superior de la figura) y cortadas tras ser ensayadas (parte inferior de la figura).

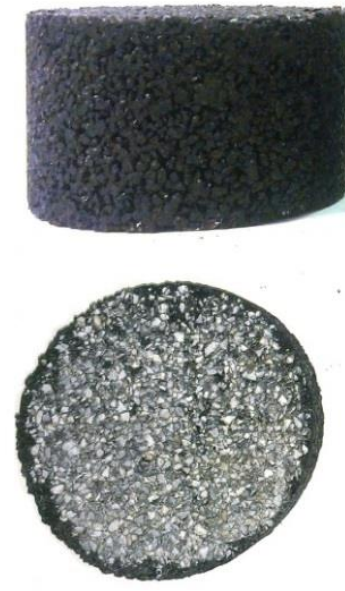

a)
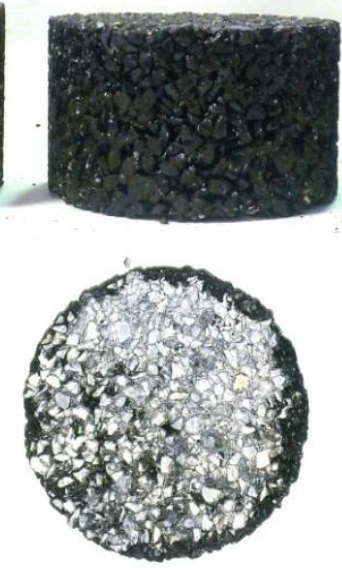

b)
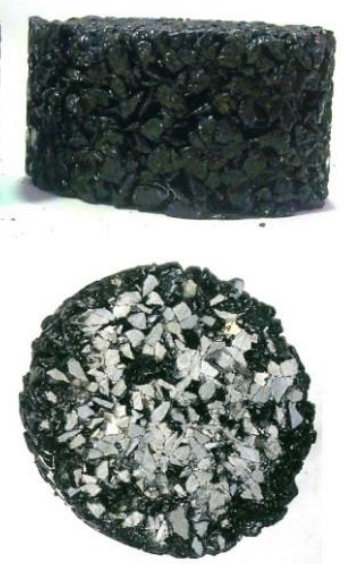

c)

Figura 14. Probetas con áridos de diferente tamaño y naturaleza: a) Caliza 2-4 mm; b) Caliza 4-6 mm; c) Ofita 4-6 $\mathrm{mm}$. 
Tabla 3. Propiedades de las mezclas

\begin{tabular}{ccccc}
\hline $\begin{array}{c}\text { Naturaleza } \\
\text { del árido }\end{array}$ & $\begin{array}{c}\text { Tamaño del } \\
\text { árido }(\mathrm{mm})\end{array}$ & $\begin{array}{c}\text { Contenido de } \\
\text { betún }(\% \mathrm{~b} / \mathrm{m})\end{array}$ & $\begin{array}{c}\text { Contenido de huecos } \\
(\%, \mathbf{N L T}-168 / 90)\end{array}$ & $\begin{array}{c}\text { Densidad de la mezcla } \\
\left(\mathbf{M g} / \mathbf{m}^{3}, \text { UNE-EN 12697-6) }\right.\end{array}$ \\
\hline Caliza & $2-4$ & 2,5 & 28,1 & 1,904 \\
Caliza & $4-6$ & 2,2 & 29,9 & 1,869 \\
Ofita & $4-6$ & 2,6 & 35,3 & 1,688 \\
\hline
\end{tabular}

\subsubsection{Ensayo}

Como variable que influye en el comportamiento de la mezcla bituminosa referida a las condiciones de ensayo, el presente trabajo se centra en el tiempo de aplicación de la carga.

Para ello, en el Laboratorio de Ingeniería de la Construcción se realizaron ensayos a deformación controlada en los que las probetas se sometían a compresión uniaxial. En estos ensayos, la probeta se sitúa en un dispositivo entre dos placas. Bajo la placa inferior, un actuador aplica la deformación controlada y sobre la superior se coloca una célula de carga fija que medirá la fuerza aplicada para mantener su posición. Durante el ensayo se registran las deformaciones verticales y horizontales mediante la colocación de extensómetros (LVDTs). Este dispositivo está situado en una cámara térmica que mantiene la temperatura constante con una precisión de $\pm 0,1^{\circ} \mathrm{C}$. La disposición del ensayo se muestra en la Figura 15.

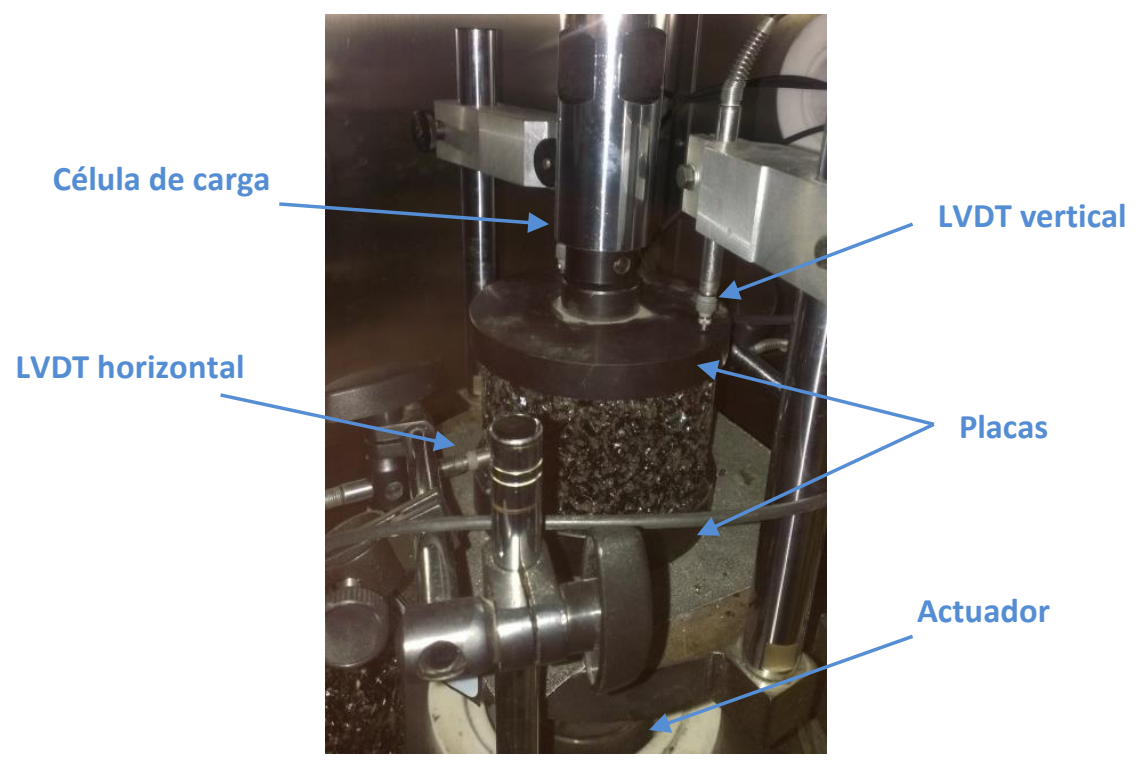

Figura 15. Disposición del ensayo

Así, en los ensayos se introducían como parámetros la deformación deseada y la aceleración y velocidad del actuador. De esta forma, se tenía una primera parte del ensayo en la que el actuador iba acelerando hasta alcanzar cierta velocidad, y una segunda fase en la que mantiene constante dicha velocidad hasta la deformación deseada. A continuación, realizaba el proceso inverso. 
Para evaluar el efecto del tiempo de carga sobre la mezcla bituminosa, se aplicaron tres aceleraciones y velocidades diferentes, buscando la misma deformación. Estas condiciones de ensayo se muestran en la Tabla 4.

Tabla 4. Condiciones de ensayo

\begin{tabular}{cccccc}
\hline TEST & $\begin{array}{c}\text { Número de probetas } \\
\text { ensayadas de cada } \\
\text { mezcla }\end{array}$ & $\begin{array}{c}\text { Deformación } \\
\text { final }(\mathbf{m m})\end{array}$ & $\begin{array}{c}\text { Aceleración } \\
\left(\mathrm{mm} / \mathbf{s}^{2}\right)\end{array}$ & $\begin{array}{c}\text { Velocidad } \\
(\mathrm{mm} / \mathrm{s})\end{array}$ & $\begin{array}{c}\text { Temperatura de } \\
\text { ensayo }\left({ }^{\circ} \mathrm{C}\right)\end{array}$ \\
\hline $\mathbf{1}$ & 4 & 0,05 & 0,025 & 0,025 & 20 \\
$\mathbf{2}$ & 4 & 0,05 & 0,05 & 0,05 & 20 \\
3 & 4 & 0,05 & 0,1 & 0,1 & 20 \\
\hline
\end{tabular}

Durante cada ensayo de laboratorio se realizaron 20 ciclos de carga y descarga para que el equipo se acomodase al mismo. Para la comparación de resultados experimentales con el modelo se utilizó el último de estos ciclos.

\subsection{Modelización}

\subsubsection{Introducción a "Particle Flow Code in Three Dimensions" (PFC3D)}

"Particle Flow Code in Three Dimensions" (PFC3D) ha sido desarrollado por ITASCA Consulting Group Inc. para modelizar el movimiento y la interacción de partículas esféricas según el Método de los Elementos Discretos descrito por Cundall y Strack (1979) (Itasca, 2008).

PFC3D modela el comportamiento dinámico de conjuntos de partículas esféricas de cualquier tamaño. Cada partícula se mueve independientemente e interacciona con las demás únicamente en los puntos de contacto. PFC3D utiliza el enfoque "soft contact" en el que las partículas se consideran rígidas pero pueden solaparse en los puntos de contacto. La magnitud del solape se relaciona con la fuerza en el contacto a través de la ley de fuerza-desplazamiento. Las partículas pueden deformar localmente en los puntos de contacto cuyo comportamiento está condicionado por la fuerza y la rigidez normal y la tangencial del mismo.

PFC3D denomina a las partículas bolas, y a los contornos paredes. El ciclo básico de cálculo en PFC3D (Figura 16) es un algoritmo paso por paso en el tiempo que requiere la aplicación sucesiva de la segunda ley de Newton (ley del movimiento) a cada partícula, la ley fuerza-desplazamiento a cada contacto, y una actualización continua de la posición de las paredes. Los contactos que pueden existir entre dos bolas o entre una bola y una pared se crean y destruyen automáticamente durante el transcurso de una simulación. PFC3D permite que los dos pasos que se describen en la Figura 16 se realicen en paralelo (Itasca, 2008). La aplicación de ambas leyes se encuentra recogida con más detalle en Itasca (2008). 

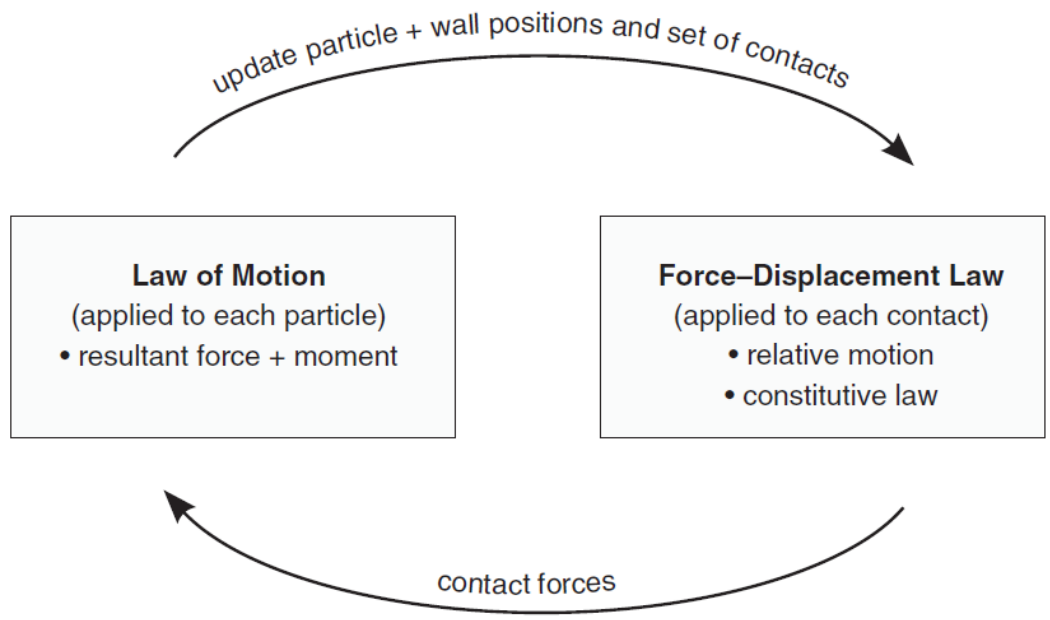

Figura 16. Ciclo básico de cálculo en PFC3D. (Itasca, 2008)

En PFC3D, las paredes permiten el confinamiento y la compactación de las partículas mediante la aplicación a las mismas de una velocidad o una fuerza a través de un algoritmo de servo-control. Durante la ejecución de dicho algoritmo, las paredes y las partículas interaccionan a través de las fuerzas de los contactos entre ellas.

PFC3D incluye dos tipos de modelos para los contactos, el modelo lineal y el modelo de Hertz, y permite introducir modelos creados por el usuario. En los modelos que incluye el programa se trabaja con tres tipos de comportamientos mecánicos de los contactos: rigidez, ligadura y fricción. En la Figura 17 se representan dos partículas adyacentes $A$ y $B$, en las que $F_{n}, F_{s}$ y $F_{r}$ son las fuerzas normal, tangencial y de fricción, respectivamente, en el contacto entre ambas. $U_{n}$ y $U_{s}$ son el desplazamiento en la dirección normal y tangencial al contacto entre ambas partículas. $K_{n}$ es la rigidez normal del contacto, y $K_{s}$ la rigidez tangencial en el mismo. $K_{n}^{[A]}, K_{n}^{[B]}, K_{s}^{[A]}$ y $K_{s}^{[B]}$ son la rigidez normal y tangencial en las partículas A y B respectivamente y $\mu$ es el coeficiente de fricción entre ellas. $S_{n}$ y $S_{s}$ son las resistencias del contacto en las direcciones normal y tangencial del mismo.

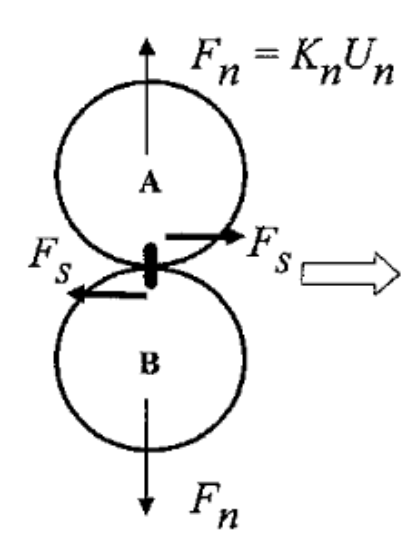

Partículas adyacentes

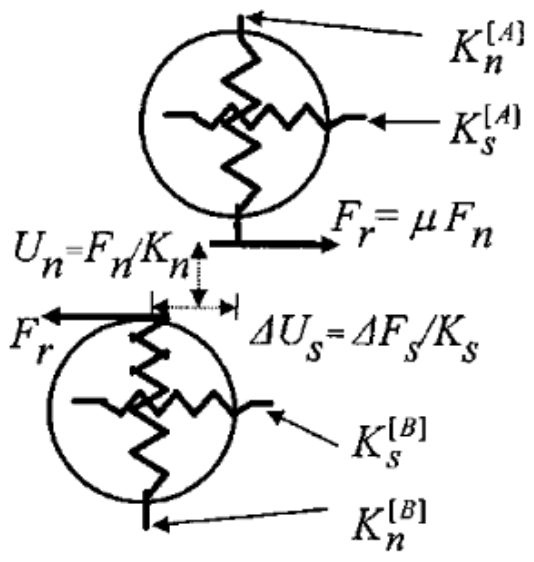

Detalle de los contactos (la fricción sólo toma parte si las ligaduras no existen

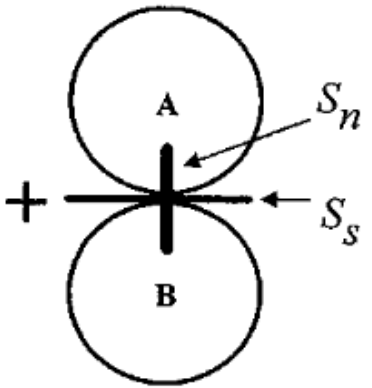

Detalle de la resistencia normal y tangencia de la ligadura

Figura 17. Detalle de las fuerzas que intervienen en el contacto entre dos partículas. (Adaptación de You y Buttlar, 
Por un lado, la rigidez proporciona la relación entre la fuerza en los contactos y los desplazamientos relativos en la dirección normal y tangencial del contacto. Por otro lado, PFC3D permite ligar las partículas en los puntos de contacto, de modo que, cuando se supera la resistencia que se ha definido para dicha ligadura, ésta se rompe. En PFC3D existen dos tipos de modelos de ligaduras: únicamente en el punto de contacto (ligadura de contacto) y/o en un disco que rodea el punto de contacto (ligadura paralela).

La ligadura de contacto (Figura 17) puede entenderse como un par de muelles elásticos (o un punto de pegamento) con rigideces normales y tangenciales constantes situados en el punto de contacto de dos partículas. Estos dos muelles tienen una resistencia a tracción y a compresión que se habrán de especificar. Por su parte, la ligadura paralela puede entenderse como un conjunto de muelles elásticos con rigideces normales y tangenciales constantes distribuidos uniformemente sobre una sección circular definida en el plano de contacto y centrada en el punto en el que éste se produce. Al igual que en la ligadura de contacto, se habrán de indicar la resistencia a tracción y a compresión, y además el radio de la circunferencia y las rigideces de los muelles. Ambos modelos de contacto pueden coexistir.

Por último, el comportamiento al deslizamiento se modela mediante la relación entre la fuerza normal y la fuerza tangencial, de modo que una partícula puede deslizar sobre otra (o sobre una pared). Si existe la posibilidad de deslizamiento, en el modelo se elimina la resistencia normal a tracción, y permite que se produzca deslizamiento mediante la limitación de la fuerza de cizallamiento. Este comportamiento siempre está presente, a no ser que se creen ligaduras de contacto. La posibilidad de deslizamiento se cuantifica mediante el coeficiente de fricción $\mu$ (adimensional), que se toma como el de menor valor de los dos elementos en contacto (Itasca, 2008).

Así, en un modelo en PFC3D se habrán de definir la rigidez normal y la tangencial de las partículas, la resistencia de las ligaduras, el coeficiente de fricción de las partículas y el coeficiente de fricción de las paredes. A partir de estos parámetros se obtendrán las características de los contactos.

\subsubsection{Modelo en PFC3D}

El primer paso para la generación del modelo en PFC3D fue definir la geometría de la probeta de ensayo. Los ensayos que se realizaron requerían la fabricación de probetas cilíndricas.

En PFC3D, se utilizan paredes para delimitar el volumen de la geometría deseada que posteriormente se rellenará con elementos. De esta forma, se definieron dos paredes cuadradas (platos) superior e inferior, y una pared cilíndrica entre ambas tal y como muestra la Figura 18. La geometría se definió en un algoritmo en el que se introducen las dimensiones de la probeta deseadas y se genera el contorno de ésta. Dicho algoritmo se encuentra recogido en el ANEXO I del presente trabajo. 


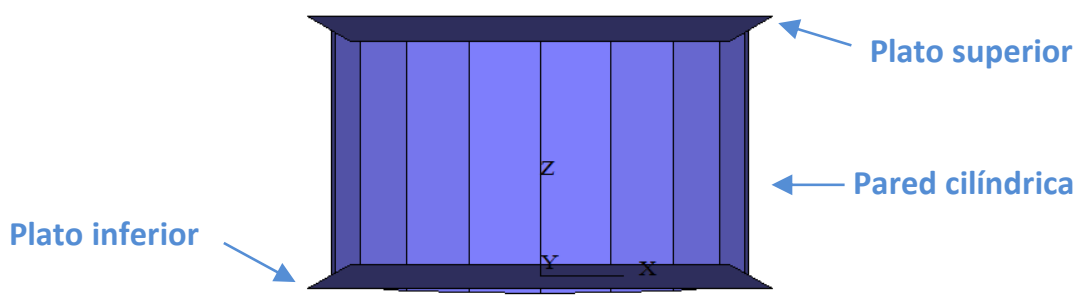

Figura 18. Geometría de la probeta

A continuación, se generó el conjunto de partículas que simularían los áridos de la probeta de laboratorio. Para definir el conjunto de partículas se utilizó un algoritmo en la que se especifican las propiedades volumétricas de las mismas y de la probeta. Así, se introducen el tamaño máximo y mínimo de las partículas, la densidad de éstas, el volumen de la probeta y la porosidad (volumen de la probeta no ocupado por partículas). A partir de estas variables se calcula el número de partículas necesario que se ha de generar para cumplir estas características. Para ello, se utiliza un procedimiento de generación de partículas por expansión del radio (Itasca, 2008).Dicho algoritmo se encuentra recogido en el ANEXO I del presente trabajo. La Figura 19 muestra un ejemplo de dicha generación.

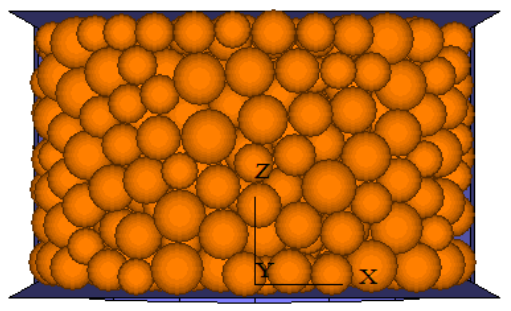

Figura 19. Ejemplo de generación de partículas

Una vez obtenidas la geometría y las partículas, se determinó el modelo de contacto a utilizar y sus parámetros. Siguiendo el objetivo principal del presente trabajo, la modelización de la mezcla bituminosa fue elástica. Así, para simular un material elástico se utilizó el modelo lineal de contacto entre las partículas proporcionado por PFC3D (Cai, 2013) y como modelo de ligadura se utilizó la ligadura de contacto (Collop et al., 2004; Lee, 2006).

En el modelo lineal, la rigidez de un contacto se calcula asumiendo que las rigideces de los elementos involucrados en el mismo actúan en serie (Itasca, 2008). Si los elementos en contacto se denominan $\mathrm{A}$ y $\mathrm{B}$, las rigideces normal $\left(K^{n}\right)$ y tangencial $\left(K^{s}\right)$ del contacto se calculan según las Ecuaciones 3 y 4 :

$$
\begin{gathered}
K^{n}=\frac{k_{n}^{[A]} k_{n}^{[B]}}{k_{n}^{[A]}+k_{n}^{[B]}} \\
K^{S}=\frac{k_{s}^{[A]} k_{s}^{[B]}}{k_{s}^{[B]}+k_{s}^{[B]}}
\end{gathered}
$$


En las que $k_{n}^{[A]}$ y $k_{n}^{[B]}$ son la rigidez normal de las partículas $\mathrm{A}$ y $\mathrm{B}$ respectivamente, y $k_{s}^{[A]}$ y $k_{s}^{[B]}$ son lason la rigidez tangencial de las partículas $\mathrm{A}$ y $\mathrm{B}$ respectivamente.

De esta forma, como propiedades mecánicas de las partículas en el modelo se especificaron la rigidez normal y tangencial de las mismas y las resistencias de las ligaduras (no se ha de especificar deslizamiento dado que la ligadura de contacto anula dicho comportamiento). Estas propiedades se introdujeron en el algoritmo de generación de partículas (ANEXO I). La Tabla 5 las propiedades iniciales de las partículas del modelo utilizadas para cada mezcla de laboratorio.

Tabla 5. Propiedades iniciales de las partículas del modelo (Wu, 2009)

\begin{tabular}{|c|c|c|c|c|c|c|c|c|}
\hline Mezcla & $\begin{array}{c}\text { Radio } \\
\text { mínimo de } \\
\text { las partículas } \\
\text { (m) }\end{array}$ & $\begin{array}{c}\text { Radio } \\
\text { máximo de } \\
\text { las } \\
\text { partículas } \\
\text { (m) }\end{array}$ & $\begin{array}{l}\text { Volumen de } \\
\text { la probeta } \\
\left(\mathrm{m}^{3}\right)\end{array}$ & $\begin{array}{c}\text { Densidad de } \\
\text { las } \\
\text { partículas } \\
\left(\mathrm{kg} / \mathrm{m}^{3}\right)\end{array}$ & $\begin{array}{c}\boldsymbol{k}_{\boldsymbol{n}} \\
(\mathrm{N} / \mathrm{m})\end{array}$ & $\begin{array}{c}k_{s} \\
(\mathrm{~N} / \mathrm{m})\end{array}$ & $\begin{array}{l}F_{n}^{C} \\
(\mathrm{~N})\end{array}$ & $\begin{array}{l}F_{S}^{C} \\
(\mathrm{~N})\end{array}$ \\
\hline \multicolumn{9}{|l|}{ Caliza } \\
\hline $\begin{array}{l}2-4 \\
\mathrm{~mm}\end{array}$ & 0,002 & 0,004 & 0,000486439 & 2,759 & $12 \mathrm{e} 6$ & $1,2 \mathrm{e} 6$ & $12 \mathrm{e} 6$ & $12 \mathrm{e} 6$ \\
\hline \multicolumn{9}{|l|}{ Caliza } \\
\hline $\begin{array}{l}4-6 \\
\mathrm{~mm}\end{array}$ & 0,004 & 0,006 & 0,000486439 & 2,807 & $12 \mathrm{e} 6$ & $1,2 \mathrm{e} 6$ & $12 \mathrm{e} 6$ & $12 \mathrm{e} 6$ \\
\hline \multicolumn{9}{|l|}{ Ofita } \\
\hline $\begin{array}{l}4-6 \\
\mathrm{~mm}\end{array}$ & 0,004 & 0,006 & 0,000486439 & 2,722 & $12 \mathrm{e} 6$ & $1,2 \mathrm{e} 6$ & $12 \mathrm{e} 6$ & $12 \mathrm{e} 6$ \\
\hline
\end{tabular}

A continuación, el modelo debía de ajustarse para conseguir que su comportamiento fuese similar al de la mezcla en laboratorio. Para ello, se fueron modificando las propiedades de los contactos entre las partículas cambiando las propiedades iniciales de éstas. Al modificar la rigidez normal y tangencial siempre se mantuvo la misma relación entre ellas tal que $k_{n} /_{k_{s}}=10$, la cual proporciona valores razonables del coeficiente de Poisson para mezclas bituminosas (Lee, 2006).

\subsubsection{Comprobaciones en el modelo}

Para asegurar un buen comportamiento del modelo, es imprescindible realizar una serie de comprobaciones en el mismo.

En primer lugar, se ha de comprobar que todas las partículas están en contacto con al menos cuatro partículas adyacentes (Lee, 2006). Para ello, en PFC3D es posible generar esferas de control en las que se monitoricen diferentes variables durante las simulaciones. En este caso, se generó una esfera de control en la que se controlaba el número medio de contactos por partícula en el volumen de la esfera (Figura 20). La generación de dicha esfera de control se encuentra recogida en el ANEXO I del presente trabajo. 


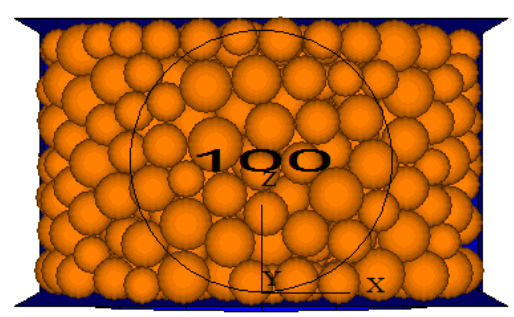

Figura 20. Esfera de control en la probeta

Por otro lado, PFC3D recomienda comprobar el estado de equilibrio de fuerzas del modelo. En equilibrio, la suma algebraica de las fuerzas debe ser muy cercana a cero (las fuerzas actuando sobre cada partícula han de estar en equilibrio). En caso contrario, se estaría produciendo un continuo movimiento de las partículas. Así, PFC3D calcula automáticamente en cada ciclo la fuerza máxima y media del conjunto de partículas. Para asegurar que estos valores son cercanos a cero, se han de comparar con las fuerzas de contacto entre las partículas para tener una referencia, es decir, se ha de saber "qué es" un valor cercano a cero. La fuerza media de contacto entre las partículas también se registra automáticamente en PFC3D en cada ciclo. Obtenidos los dos valores de fuerzas, se calcula la relación entre ambas. Así, se acepta que el cociente entre la fuerza máxima aplicada sobre las partículas y la fuerza máxima en los contactos sea menor de 0,01 en estados intermedios, y menor de 0,001 en un estado final (Itasca, 2008).

\subsubsection{Simulación del ensayo en PFC3D}

Una vez creado el modelo, y según las condiciones del ensayo de laboratorio en las que la probeta no dispone de confinamiento lateral, el primer paso fue eliminar la pared cilíndrica de la geometría mediante el comando "delete wall 1" en PFC3D (Figura 21).

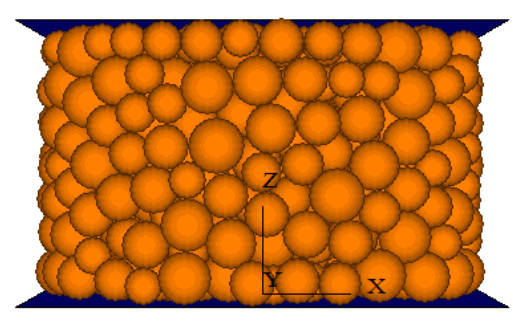

Figura 21. Configuración para el comienzo del ensayo

A continuación, se monitorizaron las variables que intervienen en el ensayo de laboratorio. Para ello, en PFC3D se utiliza un algoritmo de servo-control (ANEXO II). En él, se definen las variables que se van a controlar durante el ensayo, en nuestro caso la deformación, la tensión y la fuerza verticales. Mediante este servo-control, el programa obtiene dichas variables en cada ciclo de cálculo automáticamente. Además, estas variables se pueden almacenar en un historial y representar gráficamente, de modo que se puede controlar su evolución durante cada simulación.

Por último, se creó el fichero de entrada al programa en el que se simula el ensayo de laboratorio (ANEXO III). Para ello, la probeta se cargaba mediante la aplicación de 
velocidad a través del plato inferior de la geometría, simulando éste el actuador del dispositivo real. De este modo, se asigna una aceleración al plato inferior hasta alcanzar una determinada velocidad final. Una vez alcanzada dicha velocidad, ésta se mantiene constante durante un tiempo. La aceleración y velocidad se controlaban con un bucle en el que se iteraba tantas veces como desease el usuario. Además se introduce una variable que controlará si la velocidad es positiva, para la fase de carga de la probeta, o negativa, para la fase de descarga.

La tensión y deformación se calcularon según indican las Ecuaciones 5 y 6 :

$$
\begin{aligned}
& \sigma=\frac{F}{A} \\
& \varepsilon=\frac{d}{h}
\end{aligned}
$$

En las que $F$ es la fuerza medida, $A$ es el área sobre la que se aplica dicha fuerza (cara circular de la probeta), $d$ es el desplazamiento y $h$ la altura inicial de la probeta.

\section{ANÁLISIS DE RESULTADOS Y DISCUSIÓN}

\subsection{Análisis del modelo de PFC3D}

En la Figura 22 se muestran los resultados del modelo para cada una de las mezclas.

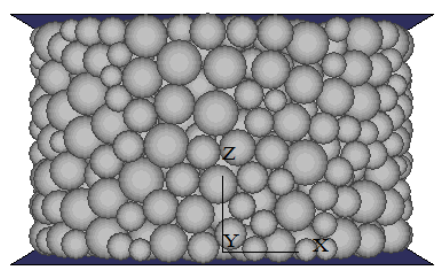

a)

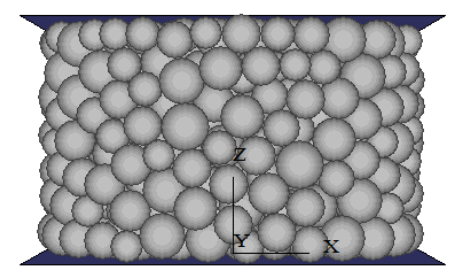

b)

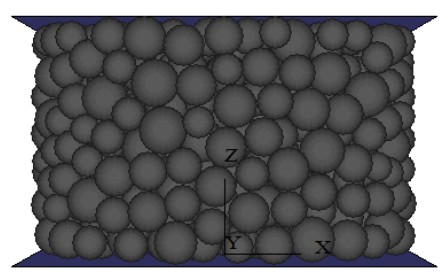

c)

Figura22. Modelos de las tres mezclas de laboratorio: a) árido calizo 2-4 mm; b) árido calizo 4-6 mm; c) árido ofítico 4-6 mm

Para llevar a cabo la comprobación volumétrica del mismo, se registraron el número medio de contactos por partícula durante la generación de éste. Los resultados se muestran en la Figura 23. En ella se observa que desde el primer momento de la generación de los tres modelos, el número medio de contacto por partículas supera el mínimo recomendado (Lee, 2006). Se observa en esta figura, que el número medio de contacto por partículas es menor en el modelo de la mezcla de árido ofítico de 4-6 mm, como se podía esperar debido a su mayor porosidad. Además, la estabilización del número medio de contactos por partícula a partir del ciclo 1000 es un primer indicador de que el modelo se encuentra en equilibrio. 
En segundo lugar, se llevó a cabo la comprobación rigurosa del estado de equilibrio del modelo. Para ello, se calculó el cociente entre la fuerza máxima en las partículas y la fuerza máxima de contacto. Los resultados se muestran en la Tabla 5, pudiéndose observar que la relación entre ambas fuerzas es menor de 0,001, tal y como se recomienda (Itasca, 2008) de forma que se considera que el modelo se encuentra en equilibrio antes de comenzar la simulación del ensayo.

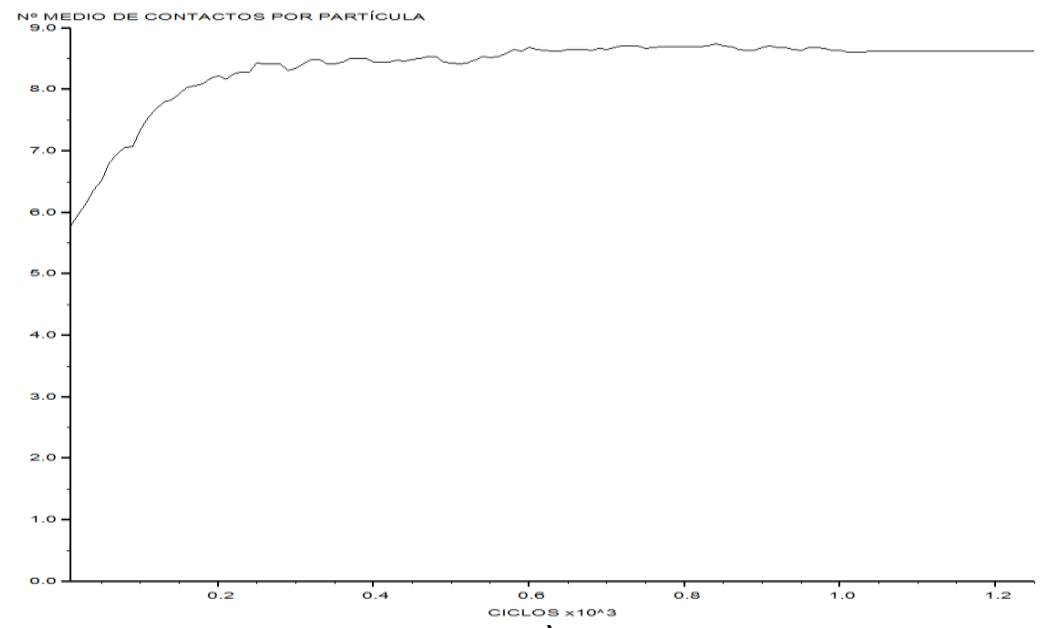

a)

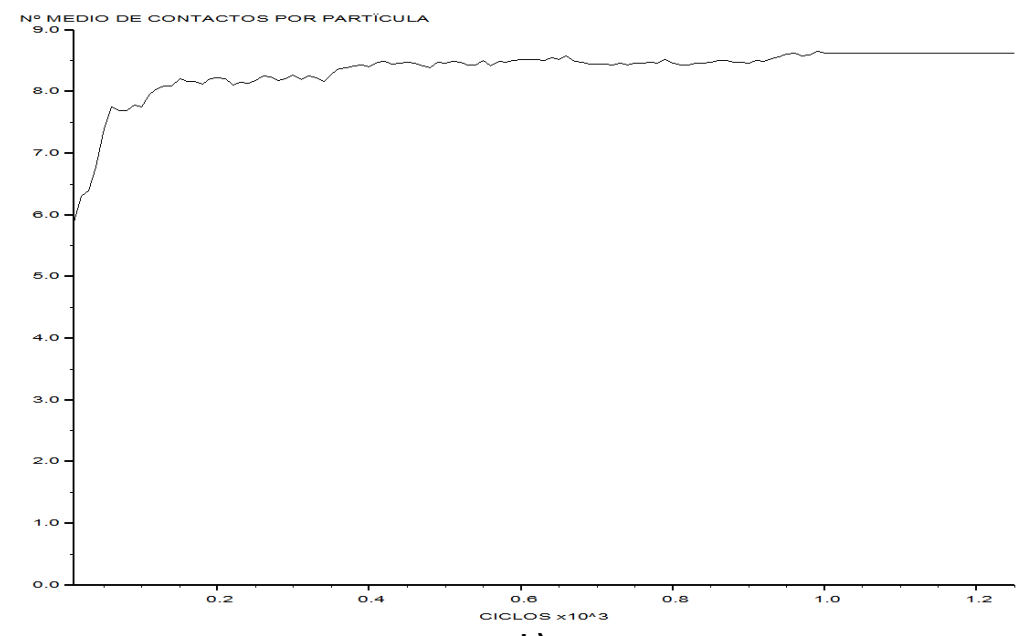

b)

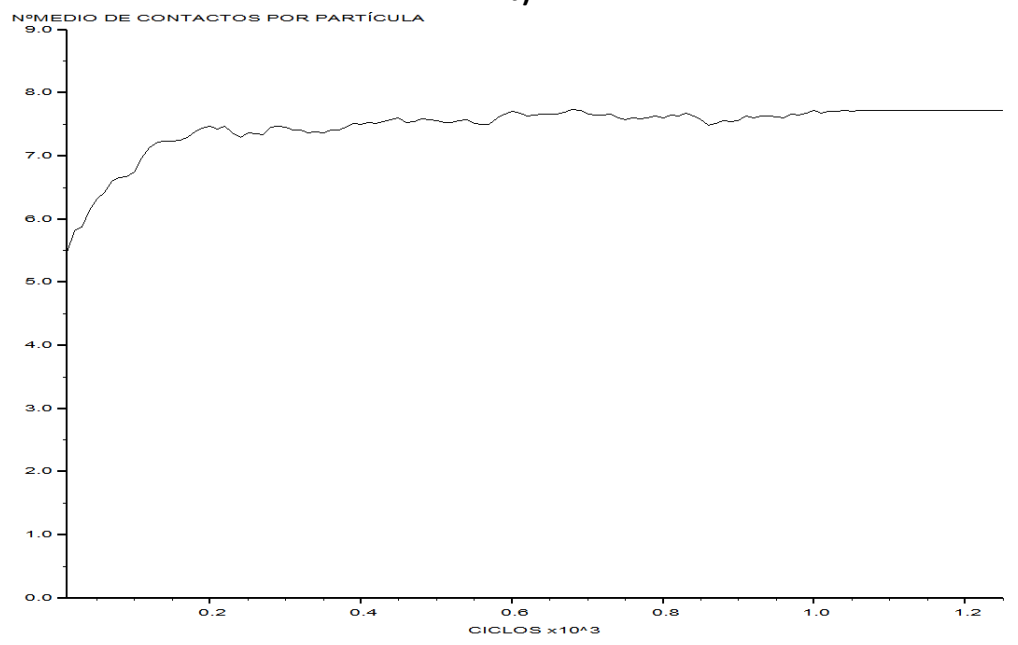

c)

Figura 23. Control del número medio de contactos por partícula: a) árido calizo 2-4 mm; b) árido calizo 4-6 mm; c) árido ofítico 4-6 mm 
Tabla 6.Relación entre la fuerza máxima en las partículas y en los contactos

\begin{tabular}{cccc}
\hline Modelo & $\begin{array}{c}\text { Fuerza máxima en las } \\
\text { partículas, } \boldsymbol{F}_{\boldsymbol{p}}(\mathbf{N})\end{array}$ & $\begin{array}{c}\text { Fuerza máxima en los } \\
\text { contactos }, \boldsymbol{F}_{\boldsymbol{c}}(\mathbf{N})\end{array}$ & $\boldsymbol{F}_{p} / \boldsymbol{F}_{\boldsymbol{c}}$ \\
\hline Árido calizo 2-4 mm & $6,95 \mathrm{e}-3$ & $1,24 \mathrm{e} 1$ & $5,60 \mathrm{e}-4$ \\
Árido calizo 4-6 mm & $3,265-5$ & $8,65 \mathrm{e} 1$ & $3,77 \mathrm{e}-7$ \\
\hline Árido ofítico 4-6 mm & $1,39 \mathrm{e}-2$ & $7,34 \mathrm{e} 1$ & $1,89 \mathrm{e}-4$ \\
\hline
\end{tabular}

\subsection{Análisis de la simulación del ensayo en PFC3D}

Previo al análisis de resultados del ensayo de la mezcla y del modelo en PFC3D, se comprobó que la simulación del ensayo era correcta. Para ello se comparan las curvas de desplazamiento del actuador, en el caso del ensayo de laboratorio, y del plato inferior, en el caso de la simulación en PFC3D. Los resultados de dichos desplazamientos en el test 1 se muestran en la Figura 24.

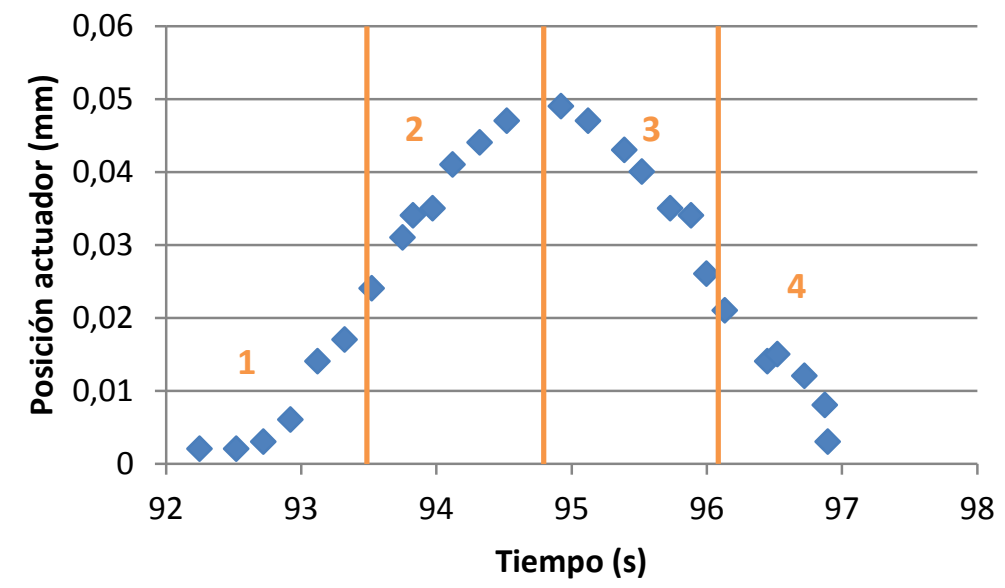

a)

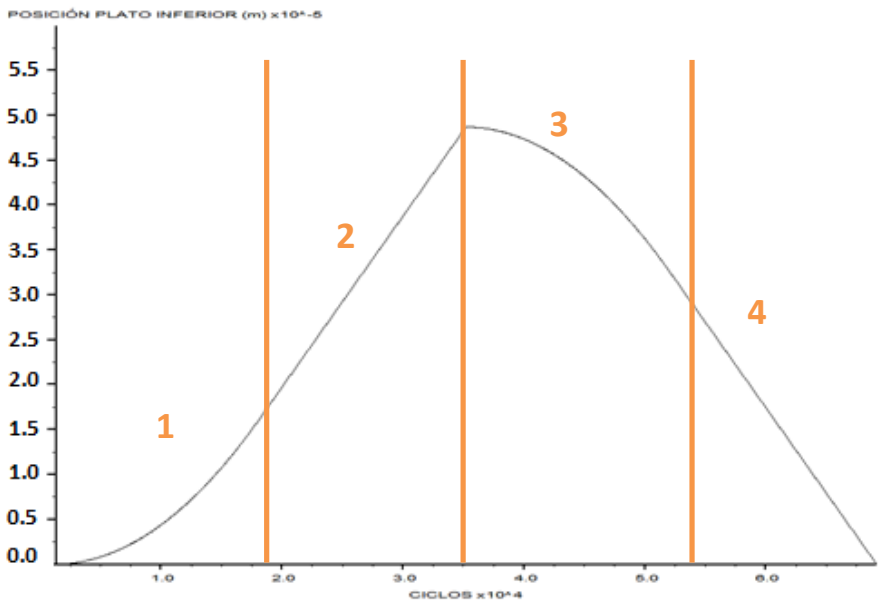

b)
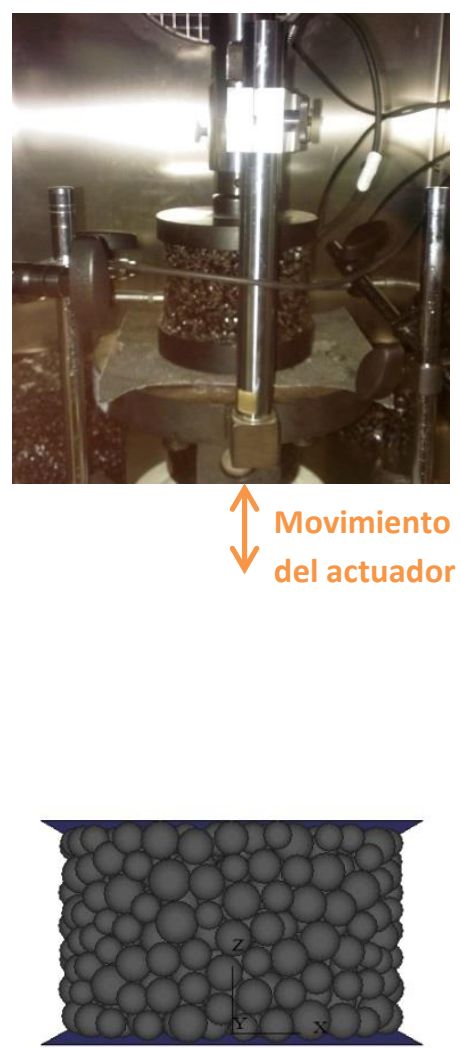

Movimiento

del plato

inferior

Figura 24. Desplazamiento de: a) actuador en el ensayo de laboratorio en el test 1 ; b) plato inferior en la simulación en PFC3D en el test 1 
Comparando las Figuras24 a) y b) se observa la concordancia de la aplicación de la deformación en el ensayo de laboratorio y en la simulación en PFC3D. En ambos casos se observan los siguientes cuatro pasos reflejados en la figura:

1. Desplazamiento hacia arriba acelerado hasta la velocidad final

2. Desplazamiento hacia arriba a velocidad constante

3. Desplazamiento hacia abajo acelerado hasta la velocidad final

4. Desplazamiento hacia abajo a velocidad constante

\subsection{Comportamiento de las mezclas ensayadas en laboratorio}

En las Figuras25, 26 y27 se muestran gráficamente los resultados de tensión-deformación en las tres mezclas de laboratorio durante el test 1 , test 2 y test 3 , respectivamente. En ellas se observa el comportamiento viscoelástico característico de las mezclas bituminosas. Por un lado, se observan los distintos recorridos durante la carga y descarga del material (la rama superior es la carga y la inferior la descarga), debido a dicho comportamiento, y por otro lado, se observa la deformación plástica no recuperada de la mezcla durante los 19 ciclos de acomodo del ensayo.

Además, en las tres figuras se puede apreciar la influencia de los distintos tamaños de árido, la naturaleza de los mismos y el tiempo de aplicación de la carga.

En primer lugar, observando las figuras 25a) y b), 26a) y b), 27a) y b) se puede concluir que el aumento de tamaño de árido calizo de 2-4 $\mathrm{mm}$ a $4-6 \mathrm{~mm}$ no provoca cambios significativos en el comportamiento de la mezcla. Este hecho puede deberse a que, a pesar de la diferencia de tamaño de árido, ambas mezclas tienen un contenido de huecos muy similar (Tabla 2) y tanto los áridos como el betún tienen la misma naturaleza. Por el contrario, en las figuras $25 \mathrm{~b}$ ) y c), 26b) y c) y $27 \mathrm{~b}$ ) y c), en las que la naturaleza del árido es distinta, las diferencias en el comportamiento se hacen más notables. La mezcla de árido ofítico presenta menor tensión que la de árido calizo para obtener los mismos niveles de deformación.

Se ha de señalar que, a pesar de ser el ensayo a deformación controlada, el bajo nivel de deformación en el que se realizaba el ensayo genera en la máquina errores de precisión, a ello se deben las diferencias de deformación final en los distintos ensayos. No se trabajó con deformaciones superiores porque no se buscaba la rotura de las probetas. Sin embargo, en estas diferencias se observa la misma tendencia en los distintos ensayos, debida a las características de las mezclas.

En cuanto al tiempo de aplicación de la carga, comparando las figuras 25, 26 y 27, se observa un aumento de la pendiente de la recta de regresión lineal representada, la cual simularía el módulo de la mezcla, a medida que aumenta la aceleración y la velocidad del ensayo. Este hecho indica que cuánto más rápida es la aplicación de la carga, el módulo de las mezclas es mayor, tal y como ocurre en la realidad. 
Ensayo de un modelo micro-mecánico para el estudio del comportamiento de mezclas bituminosas

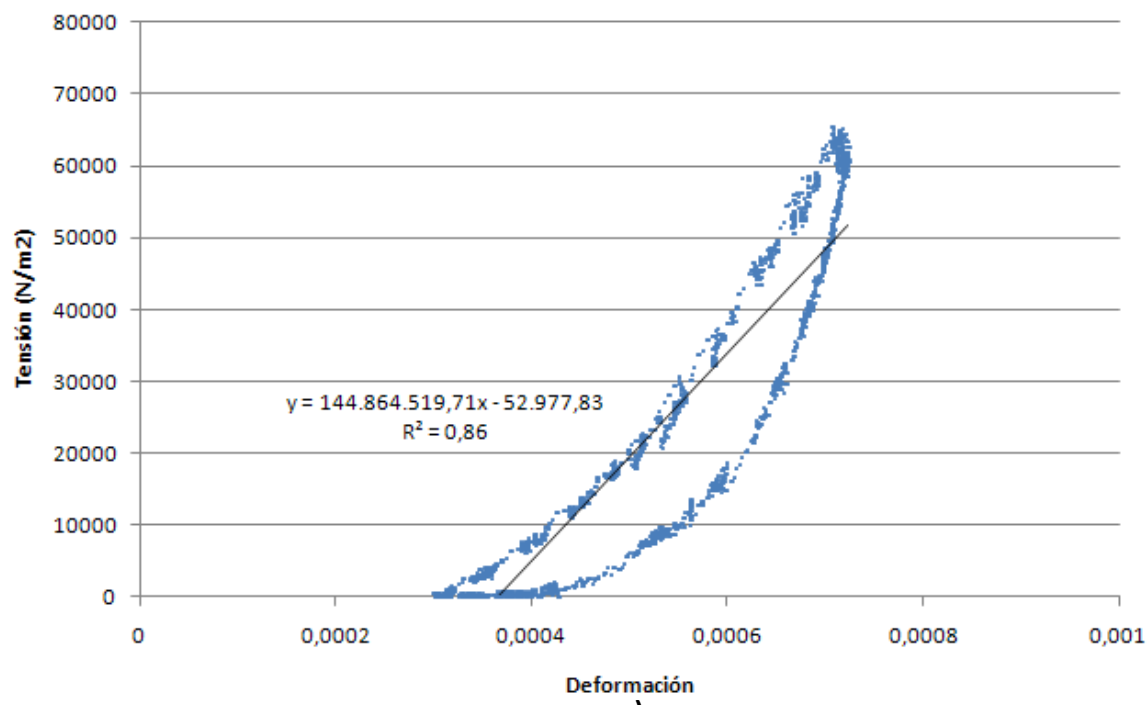

a)

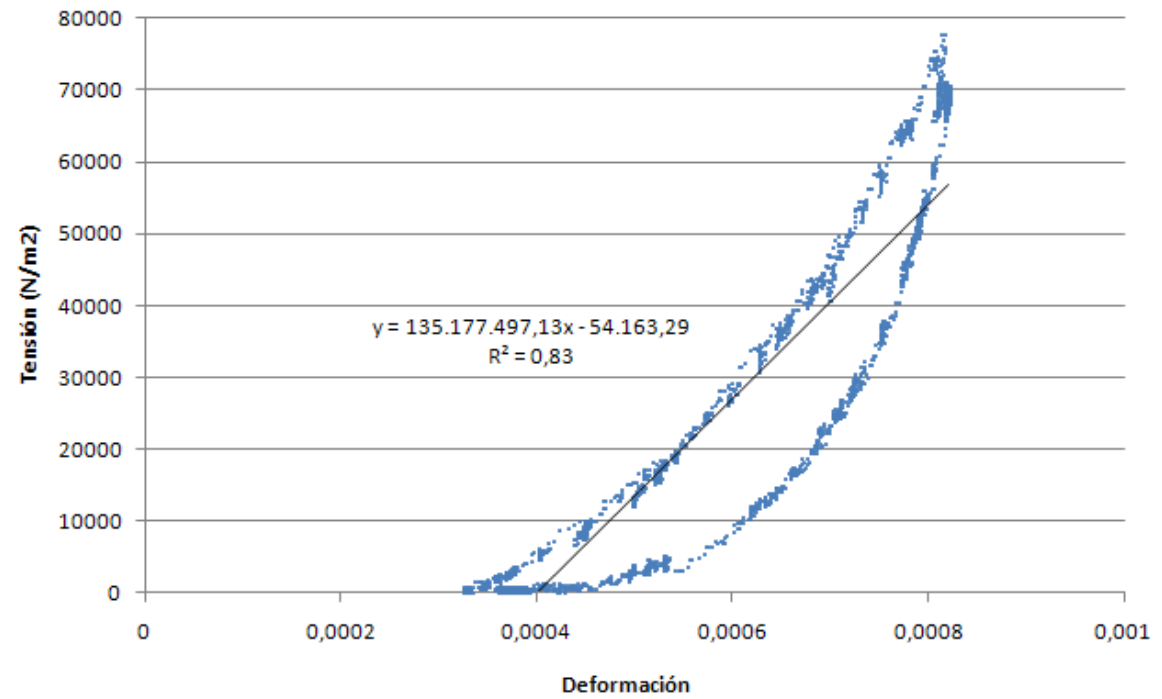

b)

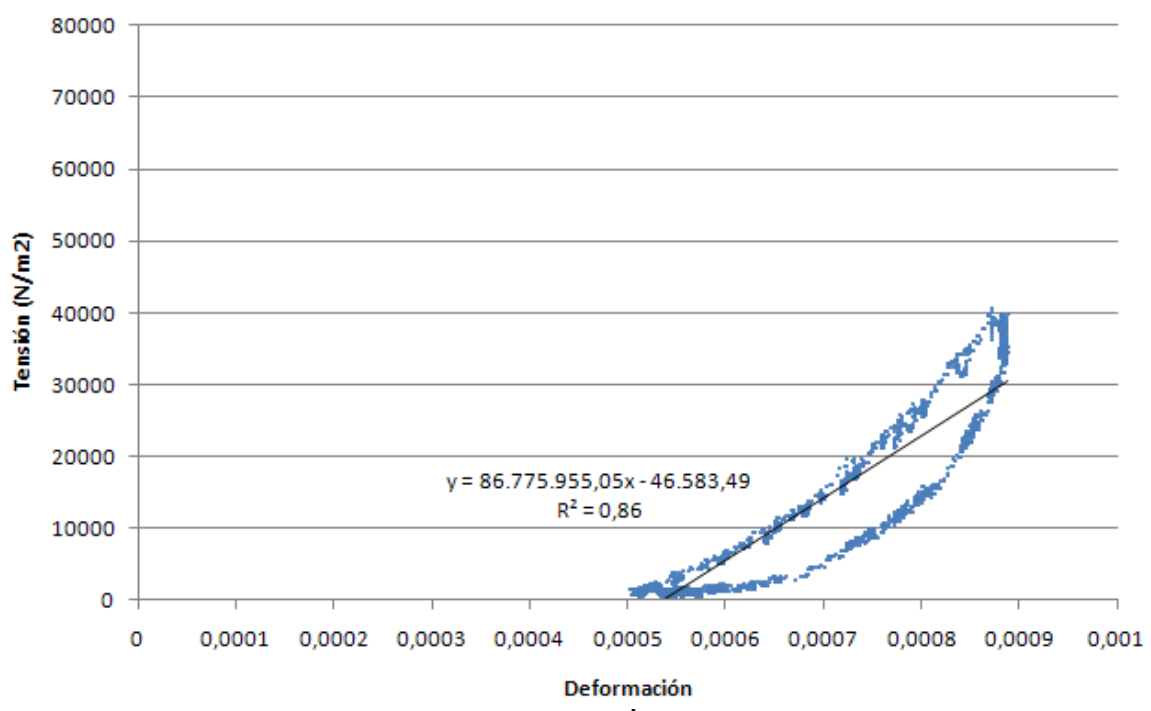

c)

Figura 25. Tensión-deformación test 1: a) mezcla de laboratorio árido calizo 2-4 mm; b) mezcla de laboratorio árido calizo 4-6 mm; c) mezcla de laboratorio ofítico 4-6 mm 


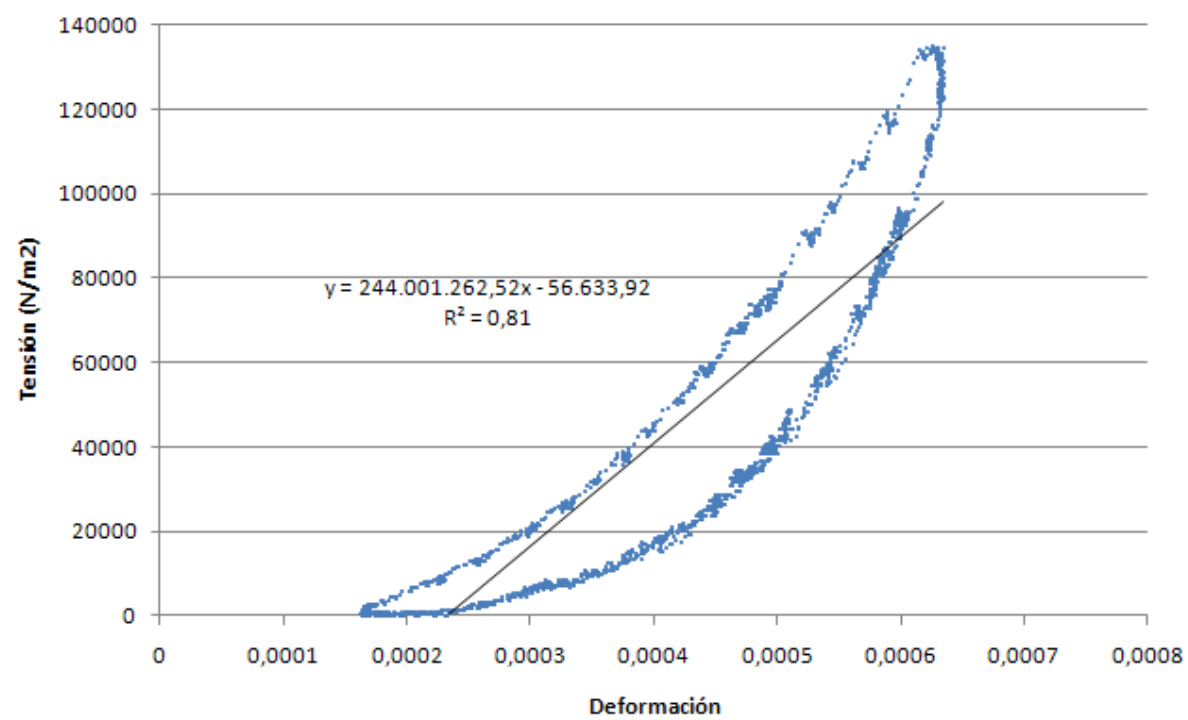

a)

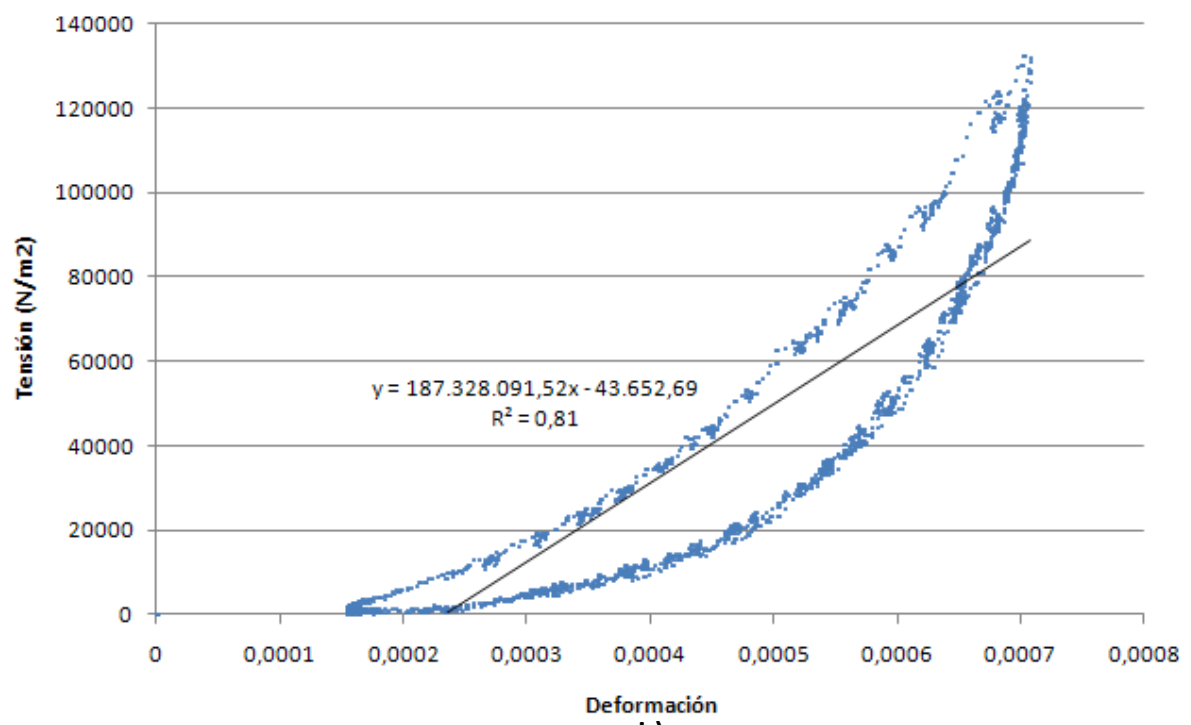

b)

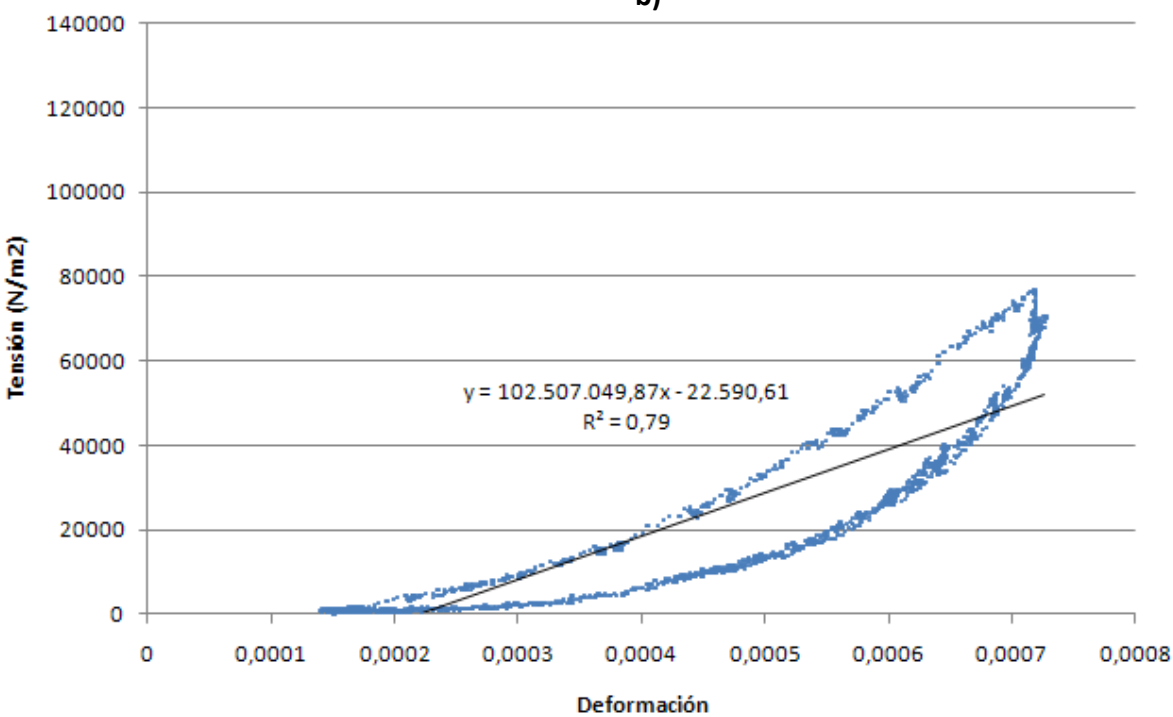

c)

Figura 26. Tensión-deformación test 2: a)mezcla de laboratorio árido calizo 2-4 $\mathrm{mm}$; b) mezcla de laboratorio árido calizo 4-6 mm; c) mezcla de laboratorio ofítico 4-6 $\mathrm{mm}$ 
Ensayo de un modelo micro-mecánico para el estudio del comportamiento de mezclas bituminosas

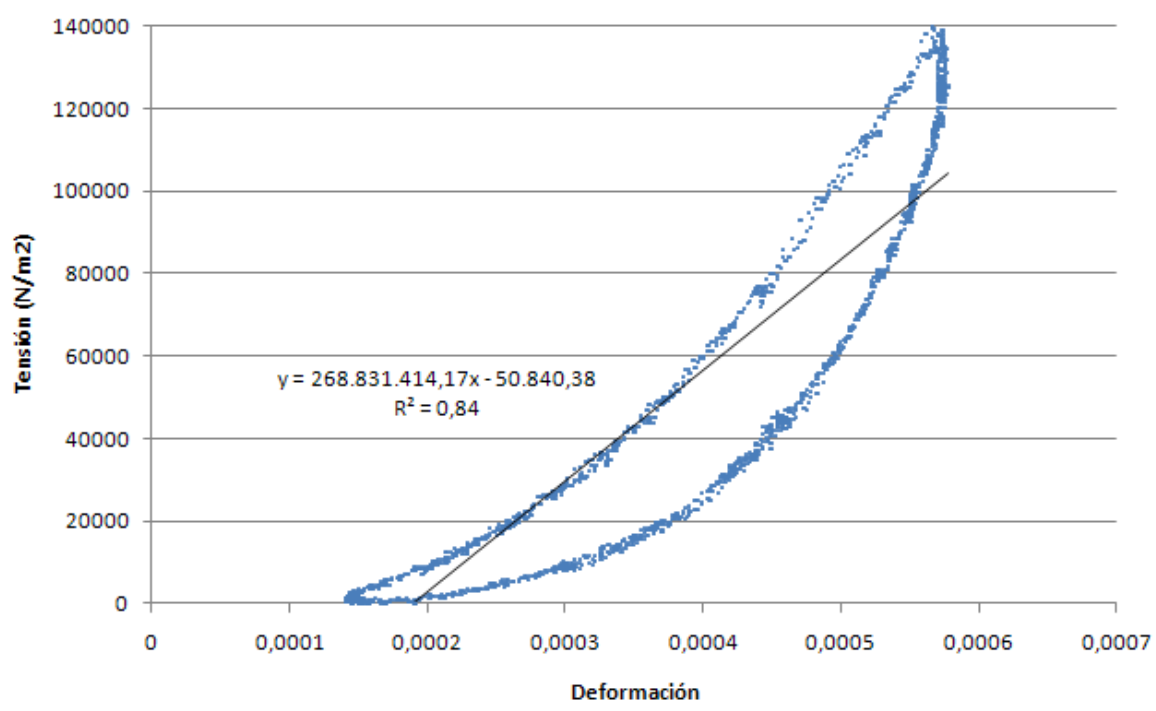

a)

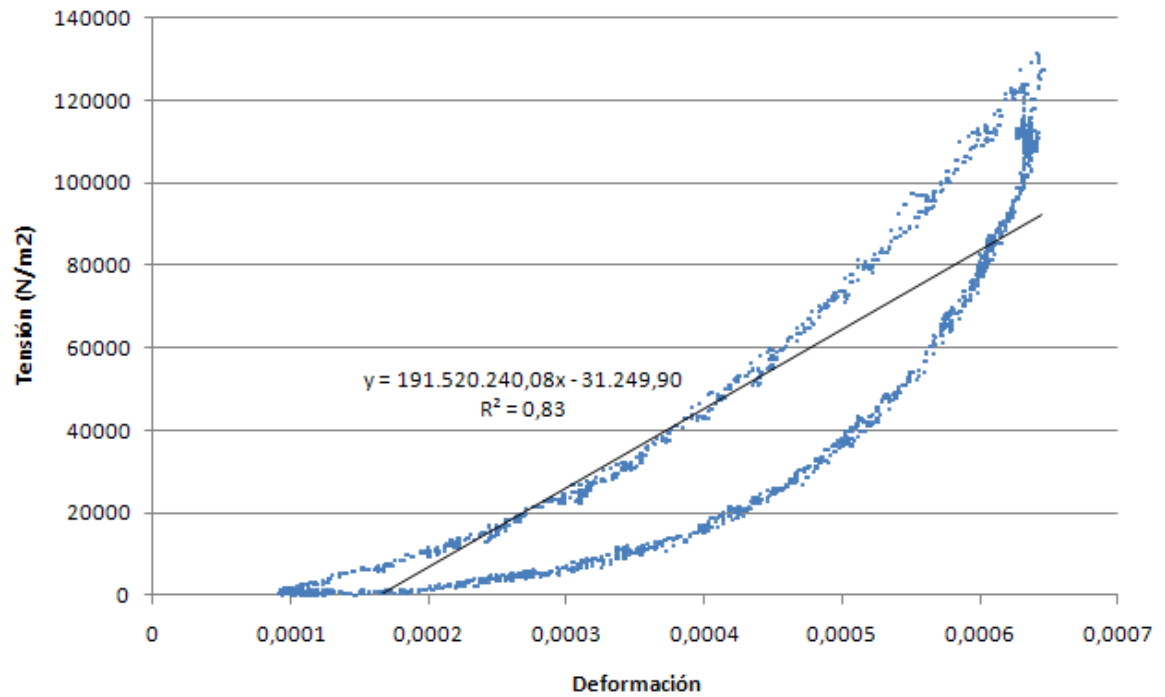

b)

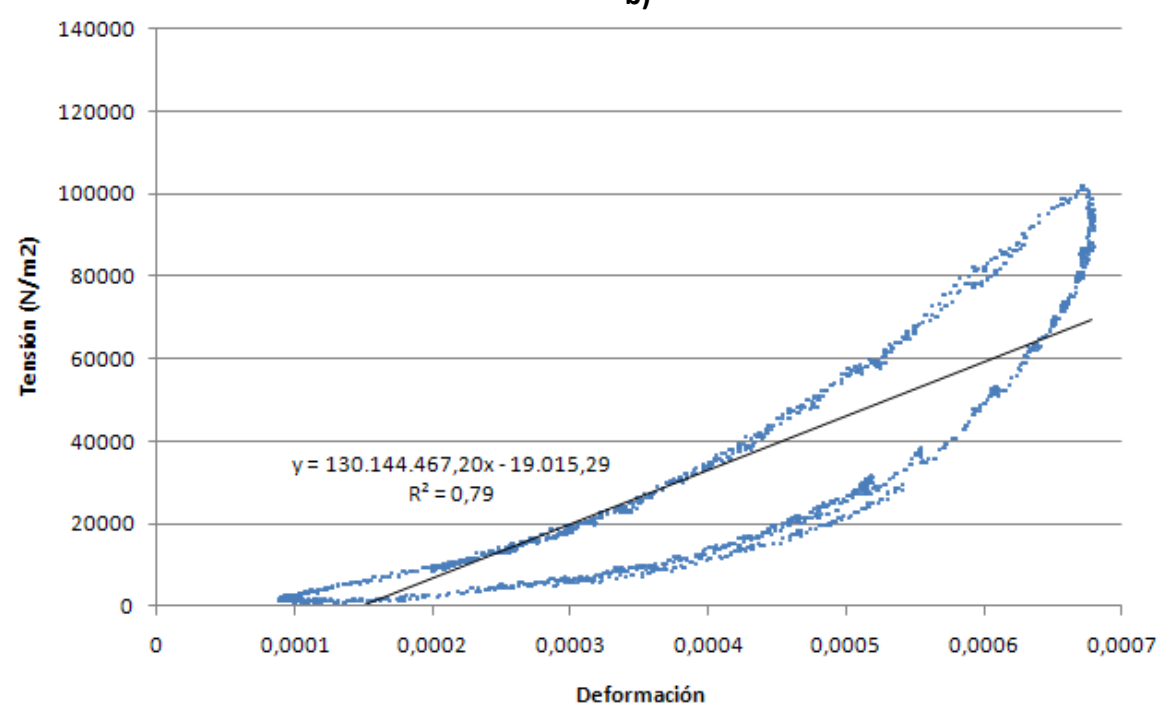

c)

Figura 27. Tensión-deformación test 3: a) mezcla de laboratorio árido calizo 2-4 mm; b) mezcla de laboratorio árido calizo 4-6 mm; c) mezcla de laboratorio ofítico 4-6 mm 


\subsection{Comportamiento del modelo en PFC3D}

En la realización de las simulaciones con PFC3D, se modela un material elástico, buscando una aproximación de módulo de Young de los ensayos realizados en laboratorio, mediante la modificación de las propiedades de los contactos. Para ello, con cada modelo se realiza la simulación de los ensayos y a la curva tensión-deformación que se obtiene como resultado se le ajusta una recta de regresión lineal. Al igual que en los ensayos de laboratorio, la pendiente de dicha recta es una aproximación del módulo de Young del material modelado. La Figura 28 muestra un ejemplo de dicho proceso.

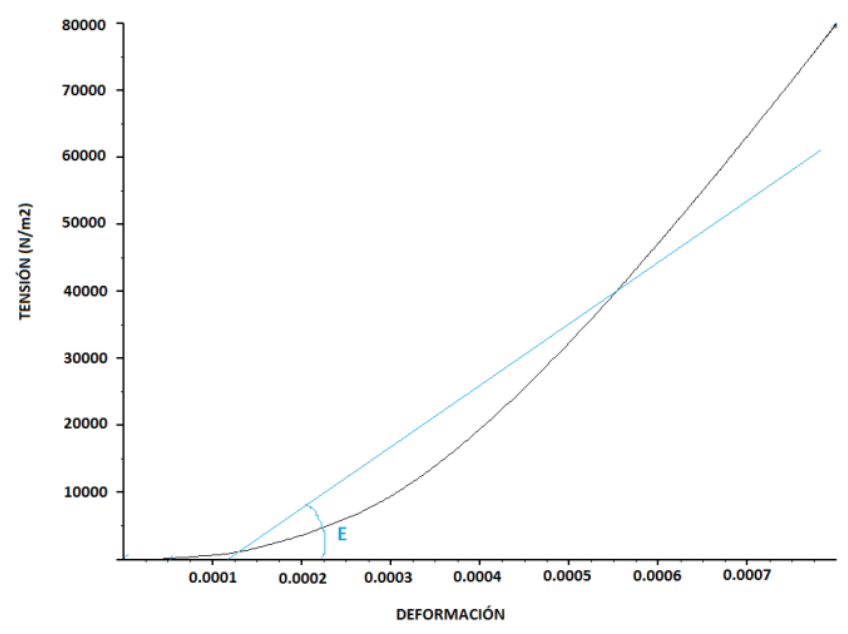

Figura 28. Obtención del módulo de Young en el modelo

Para ajustar el módulo a los resultados de laboratorio, en primer lugar, se estudió la sensibilidad del mismo a cambios en la rigidez normal y tangencial de las partículas (manteniendo la relación entre ambas). La Figura 29 muestra la comparación de tres rectas de regresión de la misma mezcla con distinta rigidez de las partículas. En ella se observa que con la misma mezcla, si se aumenta la rigidez normal y tangencial de los contactos, el módulo del material aumenta. Sin embargo, no se observó sensibilidad del modelo a cambios en las resistencias de las ligaduras de contacto.

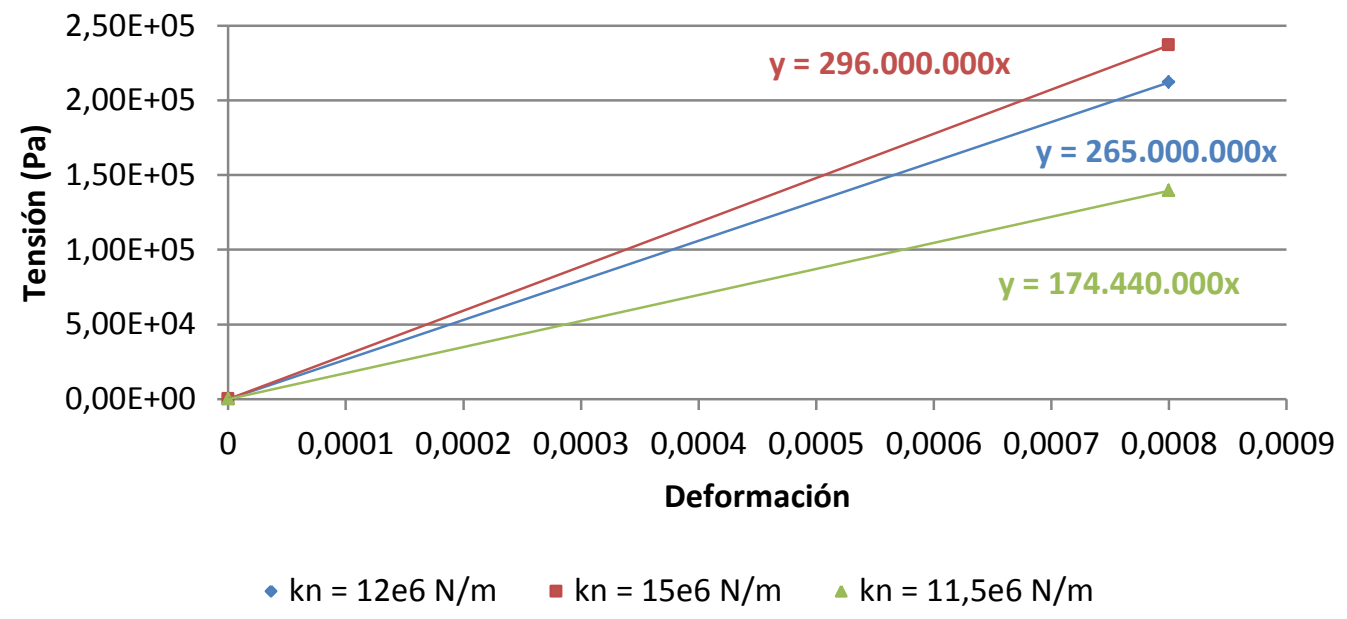

Figura 29. Módulo de Young con distinta rigidez de partículas para la mezcla de árido calizo 2-4 mm 
Por otro lado, la Figura 30 muestra la relación tensión-deformación obtenida en la simulación de los modelos de árido calizo de 2-4 mm y 4-6 mm con la misma rigidez de partículas. En ella se observa que el aumento del tamaño de partículas provoca que el módulo disminuya. Por tanto, para obtener resultados similares a los de laboratorio, en los que el tamaño del árido no afectaba significativamente al módulo, se habrá de cambiar la rigidez de las partículas.

En la Figura 31 se observa el módulo obtenido con los modelos de árido calizo de 4-6 mm y árido ofítico 4-6 mm con la misma rigidez de partículas. En ella se observa que el cambio en las propiedades debido a la naturaleza del árido ofítico hace que el módulo del modelo disminuya, igual que sucedía en los ensayos de laboratorio, pero en mayor medida. Por ello, la mezcla con árido calizo necesitará contactos con mayor rigidez para simular a la mezcla de laboratorio.

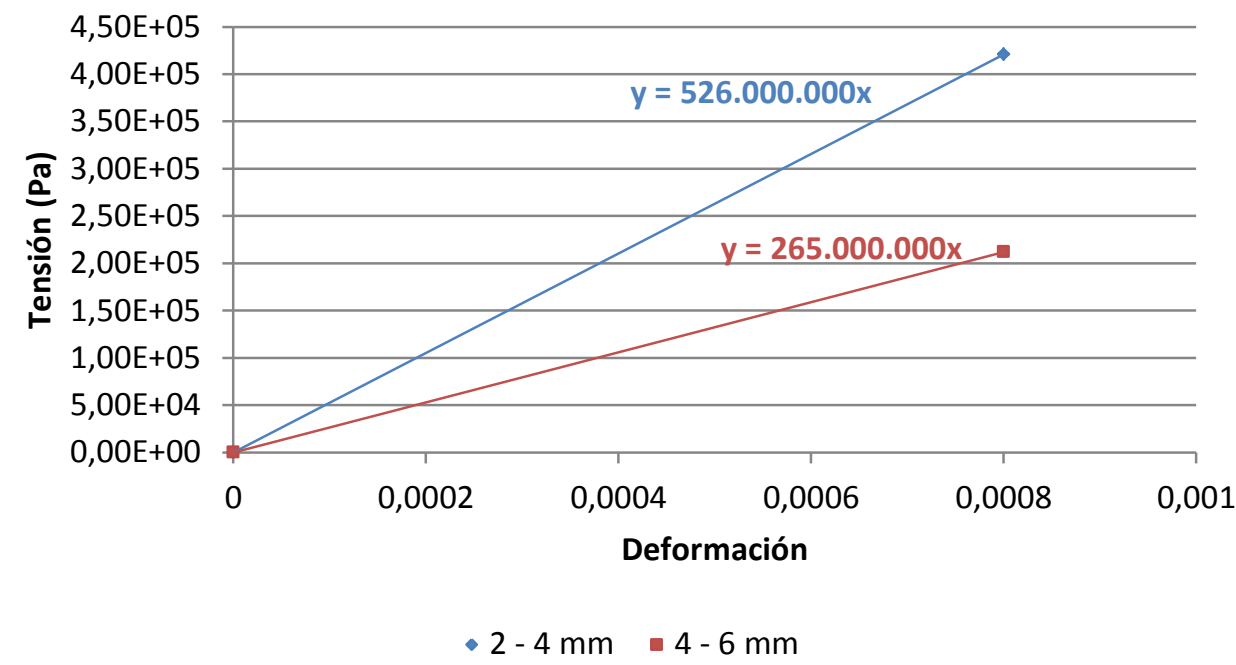

Figura 30. Módulo de Young según el tamaño de las partículas

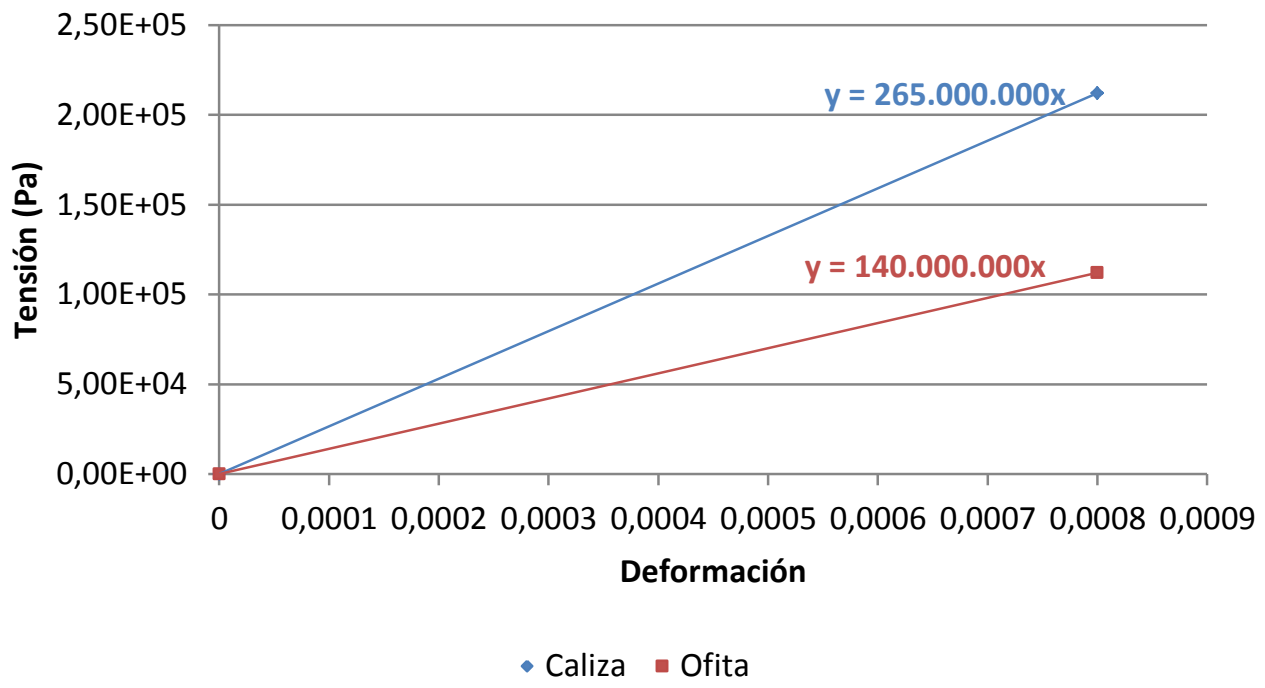

Figura 31. Módulo de Young según la naturaleza de las partículas 
De este modo, partiendo de los valores iniciales de la Tabla 5 y modificando la rigidez de las partículas del modelo según las tendencias observadas en las figuras 29,30 y 31 , éste se ajusta para obtener el mismo módulo que en los ensayos de laboratorio. Así, la Figura 32 muestra con qué rigidez se obtuvieron los módulos aproximados para cada velocidad de ensayo. En ella se comprueba que existe una relación entre la rigidez de las partículas y los cambios en la mezcla.

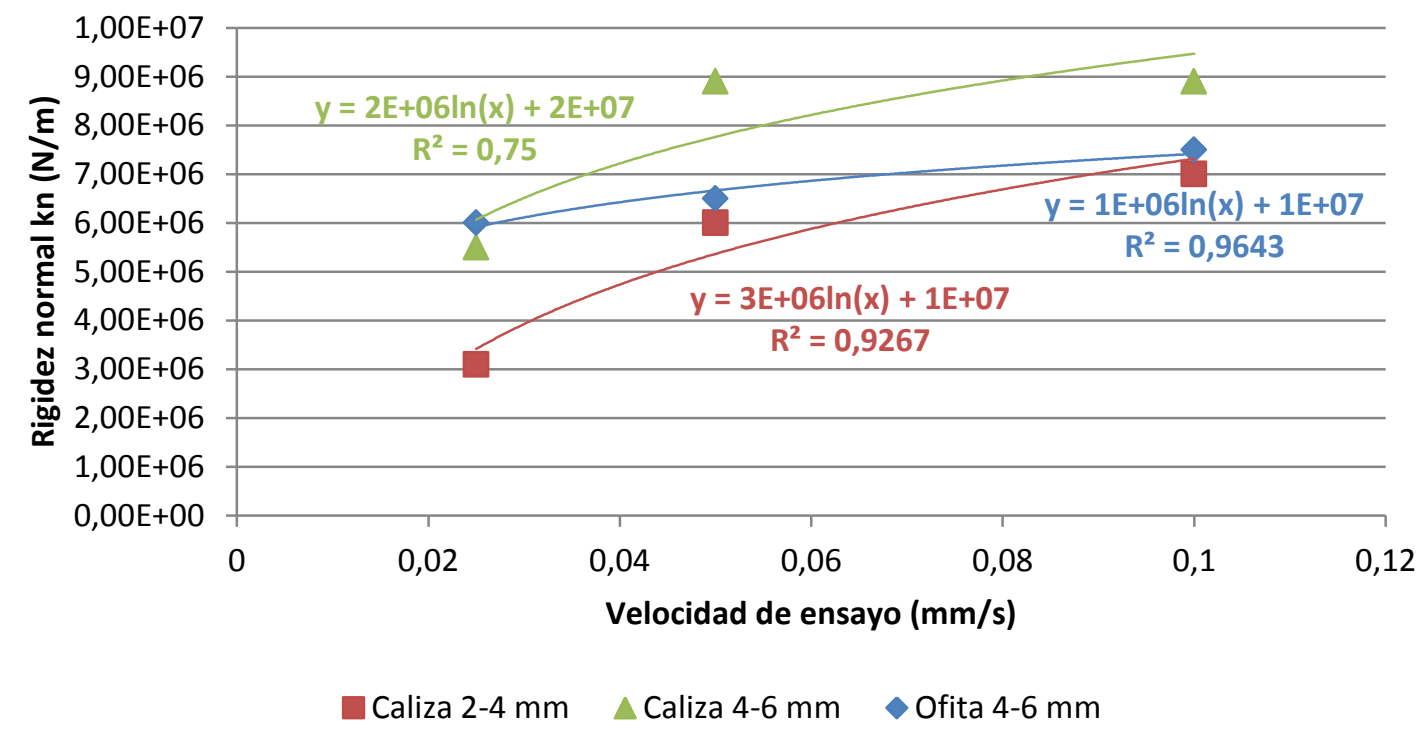

Figura 32. Rigidez normal de las partículas en función de la velocidad de ensayo

En ella se oberva que el aumento del tamaño de árido, ha de traducirse en un aumento de la rigidez de las partículas para obtener un módulo similar a la mezcla de laboratorio, y por tanto, en un aumento de la rigidez de los contactos. Por otro lado, la distinta naturaleza del árido no altera significativamente la rigidez de las partículas para velocidades bajas de ensayo, pero sí para velocidades mayores.

Además, se observa que un menor tiempo de aplicación de la carga (mayor velocidad de ensayo), ha de suponer un incremento en la rigidez de las partículas para que el modelo se ajuste a los ensayos de laboratorio, dado que éste es elástico y la velocidad de carga no influye en su comportamiento. Este hecho supone una ventaja ya que las simulaciones se pueden ejecutar con la velocidad de deformación que se desee, teniendo así menor coste computacional que en un modelo viscoelástico.

Según muestra la Figura 32, los tres modelos pueden ajustarse a una tendencia logarítmica, de modo que velocidades menores de carga influyen en mayor medida en la rigidez de los contactos que velocidades mayores.

En la Figura 33 se muestra un ejemplo de representación del modelo y la mezcla de árido calizo 4-6 $\mathrm{mm}$ en el test 1 . En ella se observa la misma tendencia de crecimiento del modelo y de la mezcla. 


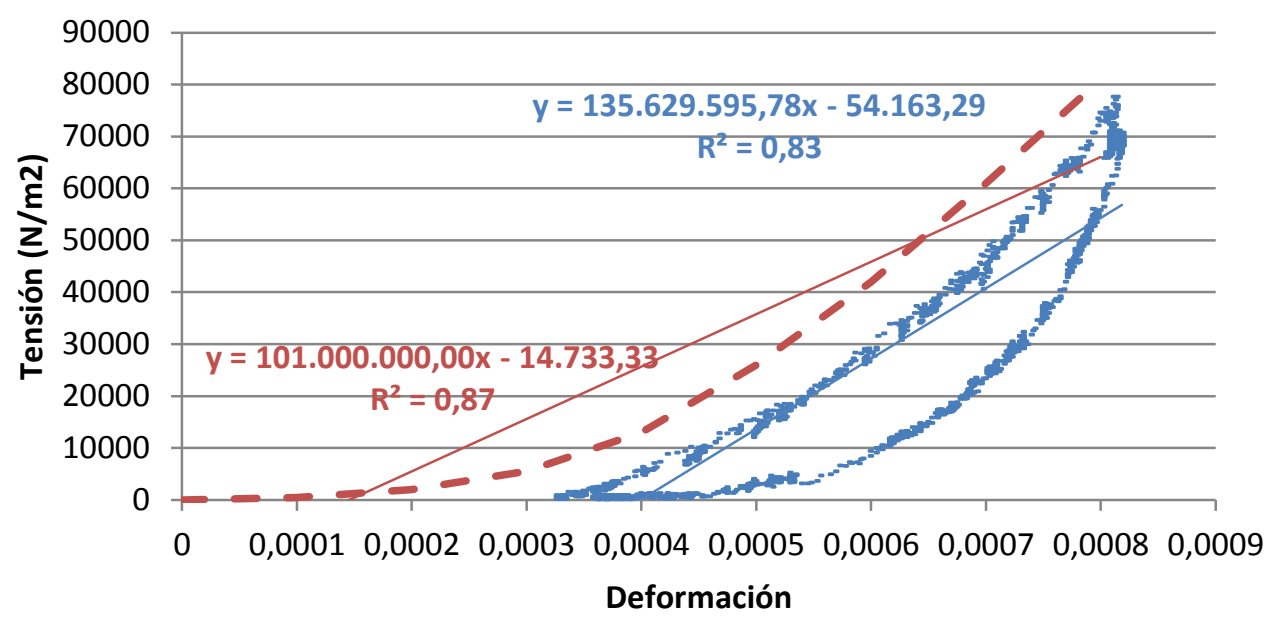

Laboratorio - Modelo

Figura 33. Comportamiento del modelo y de la mezcla de árido calizo 4-6 $\mathrm{mm}$ en el test 1

Por último, la Figura 34 muestra la relación entre el módulo en los ensayos de laboratorio y el módulo obtenido en las simulaciones con las rigideces de la Figura 32., junto con el ajuste lineal obtenido entre ambas.

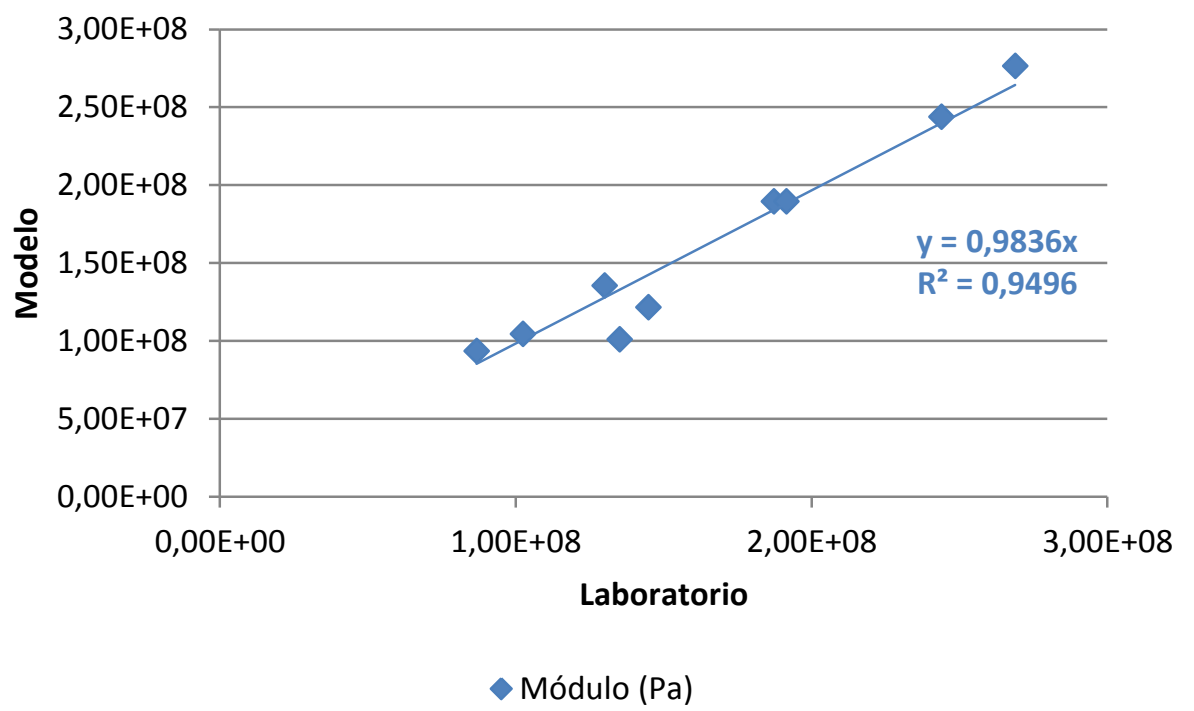

Figura 34. Relación entre el módulo en ensayos de laboratorio y simulaciones 


\section{CONCLUSIONES}

Tras la realización de los ensayos de laboratorio se puede concluir que:

- La diferencia del tamaño de árido estudiado no provoca diferencias significativas en el comportamiento de las mezclas.

- La distinta naturaleza del árido tiene como consecuencia comportamientos distintos. La mezcla con árido calizo presenta mayor módulo de rigidez que la mezcla con árido ofítico.

- El tiempo de aplicación de la carga influye de modo que cuánto menor es éste, mayor es el módulo de la mezcla.

Tras la creación del modelo y simulación de los ensayos en PFC3D, dentro del rango estudiado en el presente trabajo, se pueden extraer las siguientes conclusiones:

- El modelo es capaz de reproducir las propiedades volumétricas de la mezcla fabricada en laboratorio obteniendo un número medio de contactos por partícula adecuado y encontrándose en equilibrio estático.

- La simulación del ensayo en PFC3D reproduce las características del ensayo de laboratorio.

- El modelo es sensible al cambio en la rigidez de los contactos del mismo.

- El módulo de Young en el modelo se ajusta linealmente con el módulo en los ensayos de laboratorio.

- Las mezclas con áridos de mayor tamaño requieren contactos con mayor rigidez en el modelo. Así, el tamaño del árido influye en la rigidez de los contactos.

- Las mezclas con árido ofítico presentan mayor rigidez en los contactos que mezclas con árido calizo. Así, la naturaleza del árido influye en la rigidez de los contactos.

- El tiempo de aplicación de la carga se traduce en un cambio de rigidez en los contactos de la estructura interna de las mezclas. Con menor tiempo de aplicación, los contactos han de ser más rígidos.

- La elasticidad del modelo supone un ahorro de coste computacional frente a un modelo viscoelástico.

En definitiva, y según el objetivo del presente trabajo fin de máster, la Figura 32 es una primera aproximación para el ahorro de ensayos de laboratorio ya que, con un mayor desarrollo de la misma, con ella se podría estimar la rigidez que habrán de tener las partículas del modelo para poder predecir el módulo de la mezcla en función de la velocidad de ensayo, el tamaño de árido y la naturaleza del mismo a utilizar. 


\section{FUTURAS LÍNEAS DE INVESTIGACIÓN}

El presente trabajo fin de máster es el comienzo de una investigación de mayores dimensiones, tal y como se recoge en el apartado 3 del mismo. Así, las futuras líneas de investigación pueden dividirse en inmediatas y a largo plazo. Las líneas de investigación inmediatas son:

- Profundización en el comportamiento de las ligaduras de contacto en el modelo de PFC3D.

- Medición de las deformaciones horizontales en PFC3D.

Las futuras líneas de investigación a largo plazo son:

- Estudio de la influencia del tipo de betún en los contactos de las partículas en el modelo.

- Estudio de la influencia del tipo de compactación en los contactos de las partículas en el modelo.

- Estudio de la influencia de la temperatura de ensayo en los contactos de las partículas en el modelo.

- Estudio de la influencia de granulometrías con diferentes tamaños de árido en los contactos de las partículas en el modelo.

- Introducción del comportamiento viscoelástico de las mezclas en el modelo. 


\section{REFERENCIAS}

Abbas, R. L. (2004). Simulation of the micromechanical behavior of asphalt mixtures using the discrete element method. Tesis para la obtención del grado de Doctor en Ingeniería Civil. Washington, Department of Civil and Environmental Engineering, Washington State University.

Asociación Española de Normalización y Certificación AENOR. (2013). UNE-EN 12697. Métodos de ensayo para mezclas bituminosas en caliente. Parte 30: Preparación de la muestra mediante compactador de impactos.

Boussinesq, M.J. (1885). "Application des potentiels a l'etude de l'equilibre et du movement des solides elastiques". Gauthier-Villars, $721 \mathrm{pp}$.

Burmister, D.M. (1962). "Application of layered system concepts to design and construction of asphalt pavement". First Paving Conference, University of New Mexico, Albuquerque, EEUU, pp. 21-47.

Buttlar, W. G., You, Z. (2001). "Discrete Element Modeling of Asphalt Concrete. Microfabric Approach". Transportation Research Record, 1757, pp. 111-118.

Cai, W.(2013). Discrete Element Modelling of constant strain rate and creep tests on graded asphalt mixture. Tesis para la obtención del grado de Doctor. Nottingham, The University of Nottingham.

Chang, K.G., Meegoda, J.N. (1993). "Simulation of the Behaviour of Asphalt Concrete Using Discrete Element Method". 2nd International Conference on Discrete Element Methods.

Chang, K.G., Meegoda, J.N. (1997). "Micromechanical simulation of hot mix asphalt". Journal of Engineering Mechanics, 123, pp. 495-503.

Collop, A.C., McDowell, G.R., Lee, Y. (2004). "Use of the Distinct Element Method to Model theDeformation Behavior of an Idealized Asphalt Mixture". International Journal of Pavement Engineering, 5(1), pp. 1-7.

Cundall, P.A. (1971). "A Computer Model for Simulating Progressive, Large-scale Movement in Blocky Rock System". Symposium International Society for Rock Mechanics.

Cundall, P.A., Strack, O.D.L. (1979). "A discrete numerical model for granular assemblies". Géotechnique, 29(1), pp. 47-65.

Dai, Q., You, Z. (2007). "Prediction of Creep Stiffness of Asphalt Mixture with Micromechanical Finite-Element and Discrete-Element Models". Journal of Engineering Mechanics, 133(2), pp. 163-173. 
Dondi, G., Simone, A., Vignali, V., Manganelli, G. (2012). “Numerical and experimental study of granular mixes for asphalts". Powder Technology, 232, pp. 31-40.

Hartman, A. M., Gilchrist, M. D., Walsh, G. (2001). "Effect of Mixture Compaction on Indirect Tensile Stiffness and Fatigue". Journal of Transportation Engineering, 127(5), pp. 370-378.

ITASCA(2008).Particle Flow Code in Three Dimensions. Itasca Consulting Group Inc., Minnesota.

Lee, Y. (2006). Discrete Element Modelling of Idealised Asphalt Mixture. Tesis para la obtención del grado de Doctor. Nottingham, The University of Nottingham.

Liu, Y. (2011).Discrete element methods for asphalt concrete: development and application of user-defined microstructural models and a viscoelastic micromechanical model. Tesis para la obtención del grado de Doctor en Ingeniería Civil. Michigan, Department of Civil and Environmental Engineering, Michigan Technological University.

Masad, E., Muhunthan, B., Shashidhar, N., Harman, T. (1999). "Quantifying Laboratory Compaction Effects on the Internal Structure of Asphalt Concrete". Transportation Research Record: Journal of the Transportation Research Board, 1681, pp. 179-185.

Polacco, G., Vacin, O.J., Biondi, D., Stastna, J., Zanzotto, L. (2003). “Dynamic Master Curves of Polymer Modified Asphalt from Three Different Geometries". Applied Rheology, 13(3), pp. 118-124.

Rothenburg, L., Bogobowicz, A., Haas, R., Jung, F.W., Kennepohl, G. (1992). "Micromechanical Modelling of Asphalt Concrete in Connection with Pavement Rutting Problems". 7th International Conference on Asphalt Pavements, pp. 230245.

Schapery, R.A.(1974). "Viscoelastic Behavior and Analysis of Composite Materials", Sedeckyj (Ed.) Mechanics of Composite Materials, pp. 86-168.

Swiertz, D., Mahmoud, E., Bahia, H. (2010). "Asphalt Mixture Compaction and Aggregate Structure Analysis Techniques: State of the Art report". University of WisconsinMadison.

Taherkani, H. (2006). Experimental Characterisation of the Compressive Permanent Deformation Behaviour in Asphaltic Mixtures. Tesis para la obtención del grado de Doctor. Nottingham, Department of Civil Engineering, The University of Nottingham.

Wu, J. (2009). Discrete Element Modelling of Compression Tests for an Idealised Asphalt Mixture. Tesis para la obtención del grado de Doctor. Nottingham, The University of Nottingham. 
You, Z., Buttlar, W.G. (2004). "Discrete Element Modeling to Predict the Modulus of Asphalt Concrete Mixtures". Journal of Materials in Civil Engineering, 16(2), pp. 140146.

You, Z., Buttlar, W.G. (2005). "Application of Discrete Element Modeling Techniques to Predict the Complex Modulus of Asphalt-Aggregate Hollow Cylinders Subjected to Internal Pressure". Transportation Research Record: Journal of the Transportation Research Board, 1929, pp. 218-226.

You, Z.,Buttlar, W. G.(2006). "Micromechanical Modeling Approach to Predict Compressive Dynamic Moduli of Asphalt Mixtures Using the Distinct Element Method". Transportation Research Record: Journal of the Transportation Research Board, 1970, pp. 73-83.

You, Z., Adhikari, S., Dai, Q. (2008). "Three-Dimensional Discrete Element Models for Aspahlt mixtures". Journal of Engineering Mechanics, 134(12), pp. 1053-1063.

Yu, H., Shen, S. (2013). "A micromechanical based three-dimensional DEM approach to characterize the complex modulus of asphalt mixtures". Construction and Building Materials, 38, pp. 1089-1096. 


\section{ANEXO I: Generación de la geometría y del conjunto de partículas}

A continuación se detalla un ejemplo del fichero de entrada a PFC3D para la generación de la geometría y el conjunto del partículas para la mezcla con árido calizo de 4-6 mm.

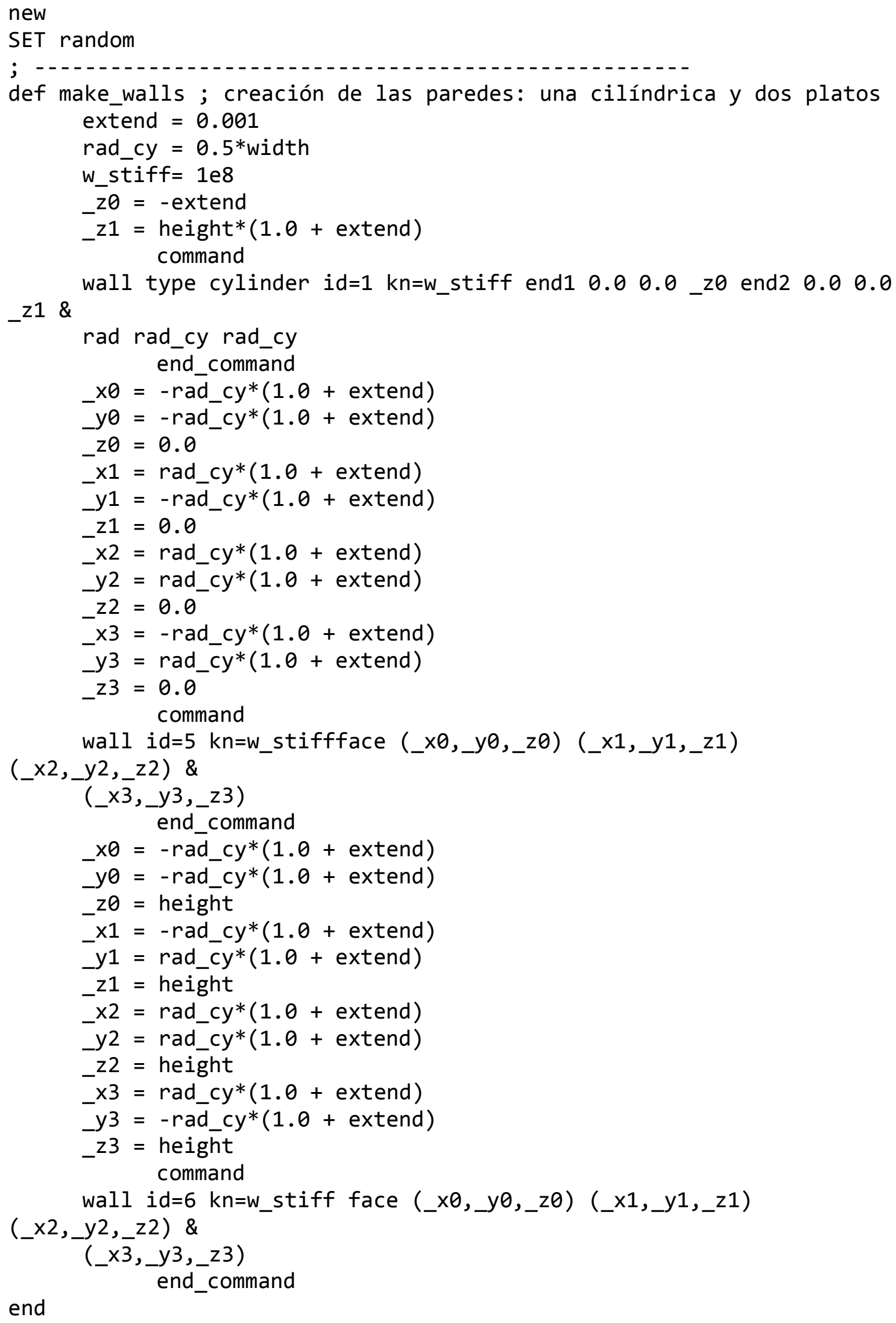

end 
;

def assemble; generación del conjunto de partículas

s_stiff $=0.7 \mathrm{e} 4$

n_stiff $=7 e 4$

tot_vol $=0.000482791$

rbar $=0.5 *($ rlo + rhi $)$

num $=\operatorname{int}((1.0-$ poros $) *$ tot_vol / $(4.0 / 3.0 * 3.1416 *$ $\left.\left.\operatorname{rbar}^{\wedge} 3\right)\right)$

$$
\begin{aligned}
& \text { mult }=1.6 \\
& \text { rlo_o }=\text { rlo } / \text { mult } \\
& \text { rhi_o }=\text { rhi } / \text { mult } \\
& \text { command }
\end{aligned}
$$

gen id=1, num rad=rlo_0, rhi_0 $x=-0.0508,0.0508 \mathrm{y}=-0.0508,0.0508$ $z=0.0$, height \&

filter $=f f \_c y l i n d e r$

prop dens $=2807 \mathrm{ks}=\mathrm{s} \_s t i f f \mathrm{kn}=\mathrm{n}$ _stiff s_bond=1e7 n_bond=1e7 end_command

$i i=\operatorname{out}\left(\right.$ string $($ num $)+{ }^{\prime}$ particulas creadas')

sum $=0.0$; obtención de la porosidad

$\mathrm{bp}=\mathrm{ball}$ head loop while bp \# null

sum $=\operatorname{sum}+4.0 / 3.0 *$ pi $*$ b_rad $(b p)^{\wedge} 3$

$b p=b \_n e x t(b p)$ end_loop

pmeas $=1.0-$ sum $/$ tot_vol

mult $=((1.0-\text { poros }) /(1.0-\text { pmeas }))^{\wedge}(1.0 / 3.0)$ command

ini rad mul mult

cycle 1250

end_command

end

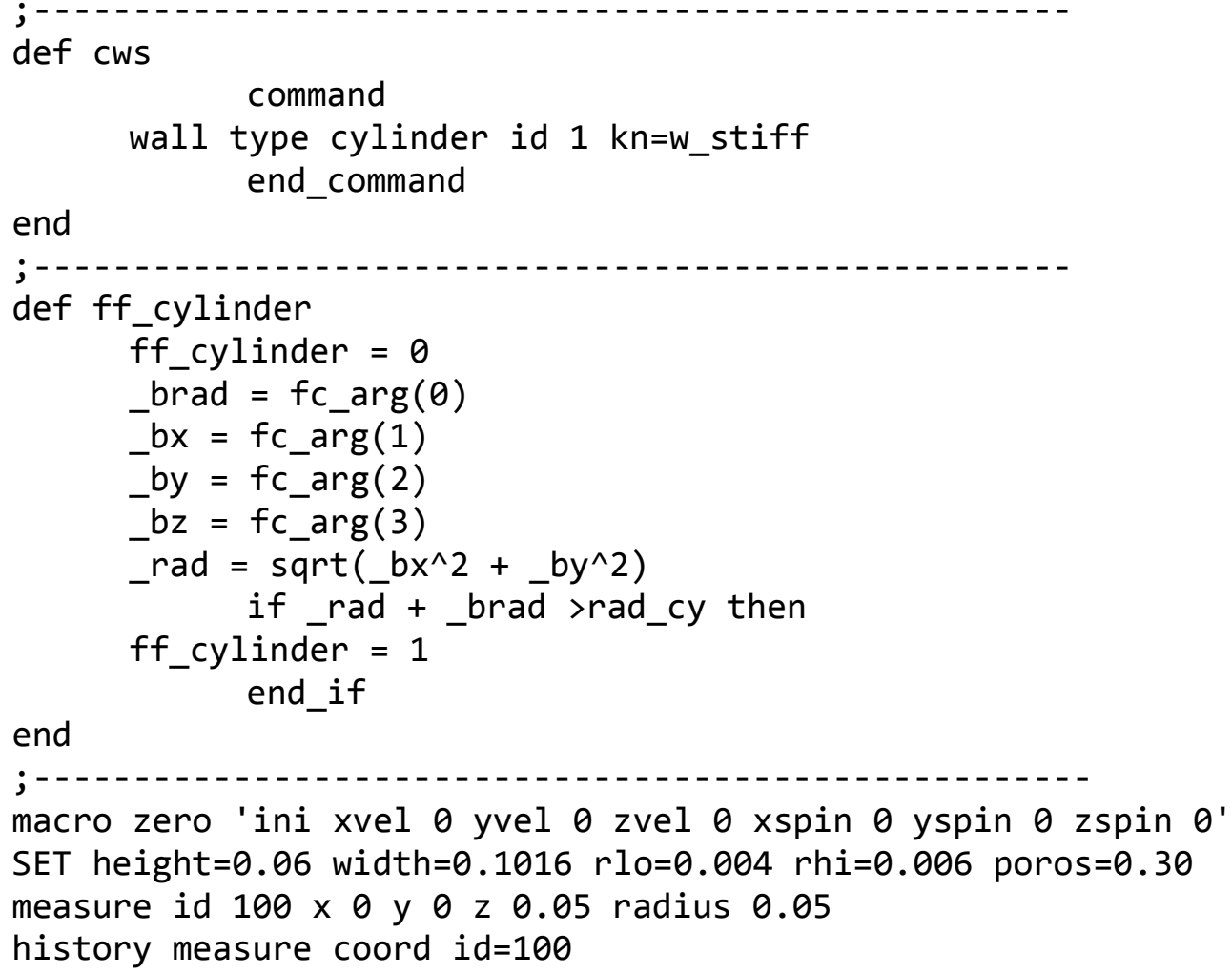

end

macro zero 'ini xvel $\theta$ yvel $\theta$ zvel $\theta$ xspin $\theta$ yspin $\theta$ zspin $\theta^{\prime}$

SET height $=0.06$ width $=0.1016 \mathrm{rlo}=0.004 \mathrm{rhi}=0.006$ poros $=0.30$

measure id 100 x 0 y $0 \mathrm{z} 0.05$ radius 0.05

history measure coord id=100 
plot create 'Coordination number 100'

make_walls

assemble

SET W_stiff= $1 \mathrm{e} 2$;

CWS

zero

;

plot create 'Probeta'

plot add ball orange

plot add wall blue

plot add axes black

plot show 


\section{ANEXO II: SERVOCONTROL}

A continuación se detalla el fichero de entrada a PFC3Dpara el control de las tensiones y deformaciones en PFC3D.

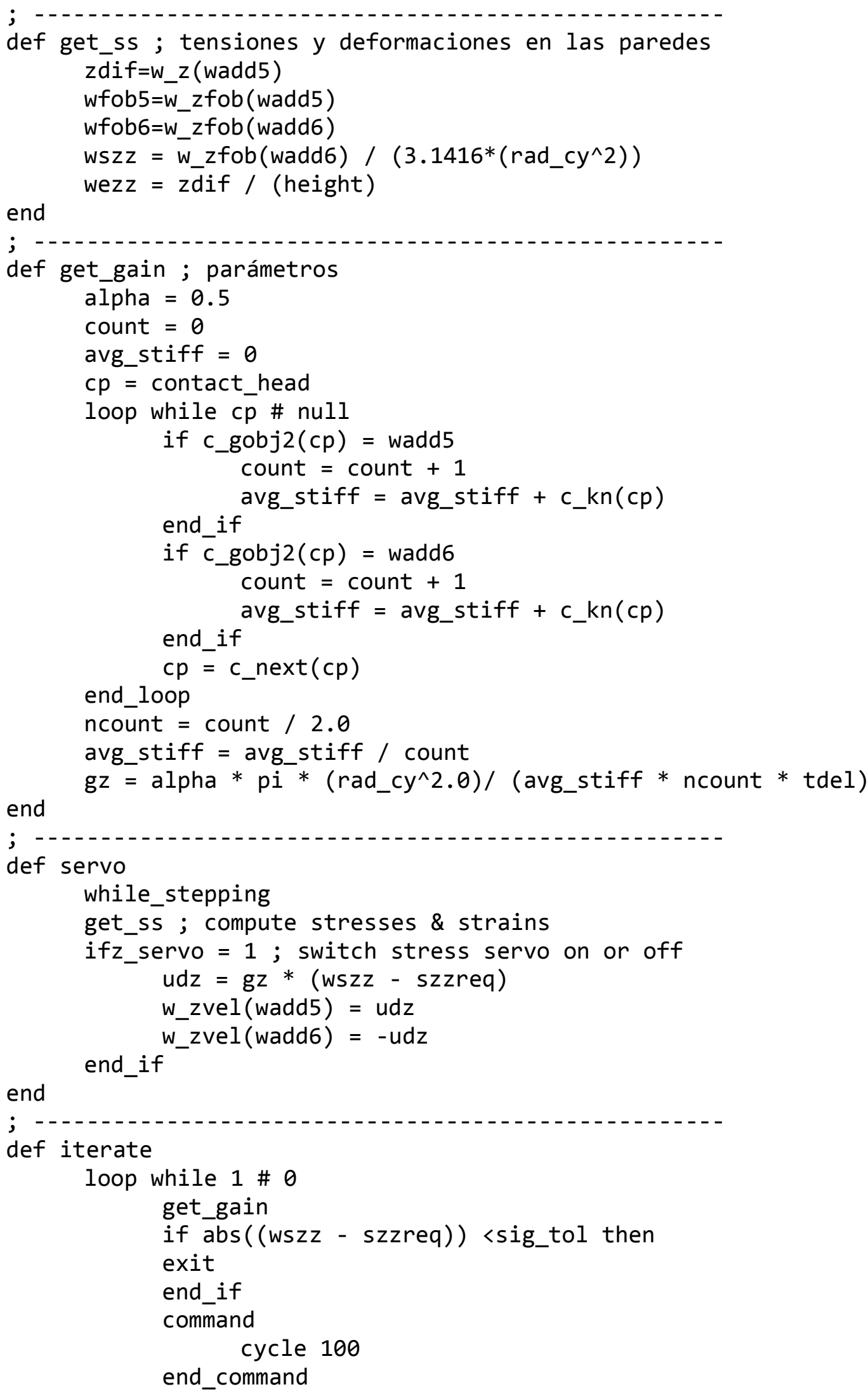


Ensayo de un modelo micro-mecánico para el estudio del comportamiento de mezclas

bituminosas

end_loop

end

;

def wall_addr

wadd5 = find_wall(5)

wadd6 $=$ find_wall $(6)$

end

; wall_addr

zero

SET szzreq=0 sig_tol $=0.0005 \mathrm{z}$ servo $=1$

iterate ; obtención de los esfuerzos requeridos

return 


\section{ANEXO III: Simulación del ensayo}

A continuación se detalla un ejemplo del fichero de entrada a PFC3D para la simulación del test 2.

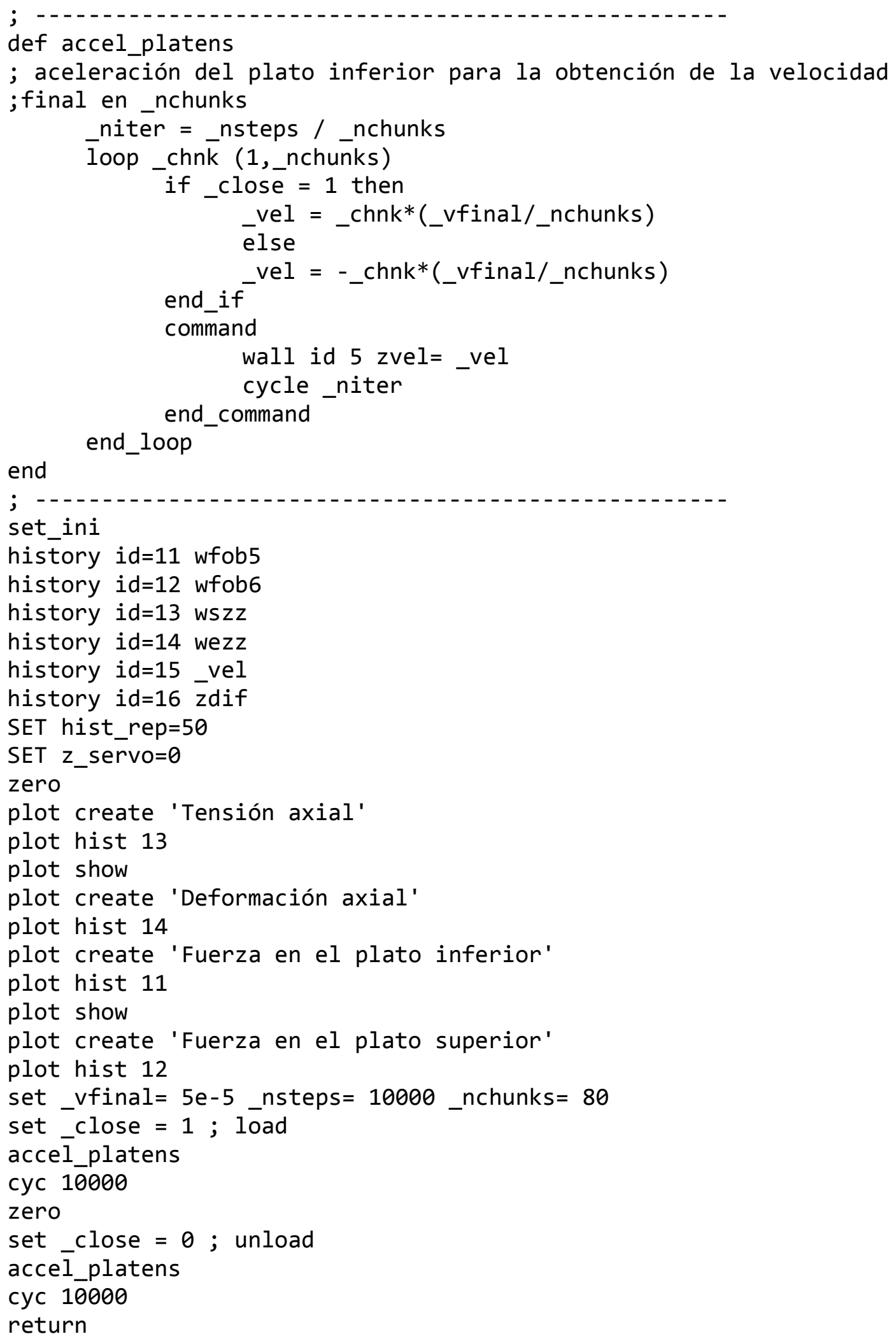


Ensayo de un modelo micro-mecánico para el estudio del comportamiento de mezclas

bituminosas 